\title{
The Diachrony of (In)definiteness-A Quantitative Study
}

\subsection{Introduction}

In this chapter we present the results obtained from the annotated corpus. We will discuss the 'profile' of a defNP and an indefNP in all languages and periods chosen for the study. We aim to establish a connection between the grammaticalizing category of definiteness and other syntactic categories such as number, gender and case, and semantic categories such as animacy.

\subsection{General Data}

We begin by presenting an overview of the data. In Chapter 3 we described the corpus built for the purposes of the project and the tool employed to annotate the texts and harvest data. As mentioned there, there are some discrepancies in terms of size between the three languages studied, the Icelandic part of the corpus being the longest. We aimed to analyse ca. 3000 NPs in each language; however, we also wished to study longer narrative passages and to do so inextenso. Tables 22 and 23 present the total percentages of definite and indefinite NPs in each language and period respectively. We will begin by discussing the overall results for defNPs.

In discussing these results, we should keep in mind that the texts in Period I represent two genres: legal prose and religious prose. As BNs are notoriously favoured in legal prose (even in modern times; see Gunnarsson 1982) this may be reflected in the results, even though we selected passages of high narrativity to avoid this as far as possible (see Chapter 3 ).

Percentage-wise there are more definite nouns in the Swedish part of the corpus than in either Danish or Icelandic, and the difference between Swedish and the other two languages is most clearly visible in Period II. Each language exhibits different results and developments in each of the three periods studied: in Danish we observe a gradual but constant rise in the frequency of the definite form, with the numbers from Period I doubling in Period II and again in Period III, resulting in triple the value from Period I in Period III. Icelandic exhibits more uniform results in all three periods, but again with the highest- 
TABLE 22 The definite nouns in the corpus - an overview

\begin{tabular}{|c|c|c|c|c|c|c|c|c|c|c|c|c|c|}
\hline \multirow[b]{2}{*}{ Language } & \multirow[b]{2}{*}{ Words } & \multirow[b]{2}{*}{ Nouns } & \multirow{2}{*}{\multicolumn{2}{|c|}{$-I N$}} & \multicolumn{3}{|c|}{ Period I } & \multicolumn{3}{|c|}{ Period II } & \multicolumn{3}{|c|}{ Period III } \\
\hline & & & & & Nouns & & -IN & Nouns & & $-I N$ & Nouns & & $-I N$ \\
\hline Danish & 15,788 & 2,900 & 349 & $12.03 \%$ & 1,097 & 67 & $6.11 \%$ & 1,016 & 139 & $13.68 \%$ & 787 & 143 & $18.17 \%$ \\
\hline Swedish & 14,533 & 2,922 & 495 & $16.94 \%$ & 1,194 & 94 & $7.87 \%$ & 1,093 & 294 & $26.90 \%$ & 635 & 107 & $16.85 \%$ \\
\hline Icelandic & 20,308 & 3,221 & 330 & $10.25 \%$ & 1,536 & 157 & $10.22 \%$ & 1,037 & 91 & $8.78 \%$ & 648 & 82 & $12.65 \%$ \\
\hline
\end{tabular}

TABLE 23 Indefinite nouns in the corpus-an overview

\begin{tabular}{|c|c|c|c|c|c|c|c|c|c|c|c|c|c|}
\hline \multirow[b]{2}{*}{ Language } & \multirow[b]{2}{*}{ Words } & \multirow[b]{2}{*}{ Nouns } & \multirow{2}{*}{\multicolumn{2}{|c|}{ EN }} & \multicolumn{3}{|c|}{ Period I } & \multicolumn{3}{|c|}{ Period II } & \multicolumn{3}{|c|}{ Period III } \\
\hline & & & & & Nouns & & EN & Nouns & & EN & Nouns & & EN \\
\hline Danish & 15,788 & 2,900 & 147 & $5.07 \%$ & 1,097 & 16 & $1.46 \%$ & 1,016 & 78 & $7.68 \%$ & 787 & 53 & $6.73 \%$ \\
\hline Swedish & 14,533 & 2,922 & 143 & $4.89 \%$ & 1,194 & 24 & $2.01 \%$ & 1,093 & 70 & $6.40 \%$ & 635 & 49 & $7 \cdot 72 \%$ \\
\hline Icelandic & 20,308 & 3,221 & 42 & $1.30 \%$ & 1,536 & 14 & $0.91 \%$ & 1,037 & 21 & $2.03 \%$ & 648 & 7 & $1.08 \%$ \\
\hline
\end{tabular}

percentage in Period III. Finally, Swedish begins with similar results to Danish in Period I, but peaks in Period II to reach a lower percentage of definites in Period III.

The variation in Icelandic is, at least superficially, marginal, and the results in all three periods are quite similar. A fact often noted in the literature on Icelandic is how little the language seems to have changed (with respect to morphology and syntax) between 1200 and modern times (e.g., Friðriksson 20o8). This would perhaps mean that the definite article in Icelandic is already well-developed in Period I, while in Danish and Swedish it seems to be a form intermediate between the original demonstrative and the target definite article. We will return to this hypothesis by the end of this chapter.

The very high percentage for Swedish in Period II also calls for closer inspection. It may be a result of the dominant genre of the period (religious prose) with many definite abstract nouns, such as högfärdh-in 'pride-DEF' (Skrzypek 2012:146-151). The tendency to mark abstract nouns as definite is present in Modern Swedish as well (e.g., Kärleken är blind, lit. 'The love is blind'; Perridon 1989:174). Interestingly, Danish and Swedish have similar values in both Period I and Period III, the significant difference between them being found in Period II. In modern Danish and Swedish defNPs differ in terms of their internal structure in the presence of modifiers - in Swedish the definite suffix is 
used with modifiers (see section 2.4.1 on double definiteness), while Danish uses the pre-adjectival definite article only (see also Chapter 1 on NPs in North Germanic). This does not, however, account for the differences found in the periods studied, as double definiteness has not yet become fully established. In the Swedish corpus the incipient definite article is combined with the preposed definite article (i.e., in a double definiteness structure) only in $1.06 \%$, $12.59 \%$ and $16.82 \%$ of uses of defNPs in the three periods respectively. Further, we even find some examples of double definiteness structure in Danish as well (in $5.76 \%$ of defNP uses, only in Period II). The difference in frequencies of -IN in Period II is thus most probably connected to the type of texts and referents that they include.

Where the grammaticalizing indefinite article is concerned, the division between Continental (Danish and Swedish) and Insular (Icelandic) languages is very pronounced. While Danish and Swedish return very similar results- the overall percentage of NPs with EN is similar in both languages, and the trend across periods also indicates similarities, with lower frequencies in Period I and higher in Periods II and III - the results for Icelandic are lower in Period I and remain lower, which may be an indication of the fact that the grammaticalization of the indefinite article does not take place in the timeframe of our study. Indeed, Icelandic has not developed the indefinite article (so far), although there seem to have been some article-like uses of the numeral EN in its history, beyond Period III as defined here (see Kliś 2019).

We must bear in mind that EN signifies both a pure numeral and the incipient indefinite article (see Chapter 2, grammaticalization of the indefinite article). Even though there is no indefinite article in Icelandic we naturally find the numeral EN, and such results and examples will be reported here. The general results presented in this section indicate that as early as the 1200 Icelandic differed from Danish and Swedish, and that differences between them persist until 1550. The definite article seems to have been well-developed as early as Period I in Icelandic. The indefinite article does not grammaticalize at all. Although Danish and Swedish also exhibit some mutual differences, they follow roughly the same path from article-less languages to languages with both definite and indefinite articles.

It would naturally be interesting to examine how the results in Tables 22 and 23 compare with modern data. It is unfortunately not feasible to obtain data from large corpora including frequencies of suffixed definite articles in the Nordic languages without conducting an in-depth study. It is, however, possible to compare the frequencies of indefinite articles in present-day Swedish, Danish and Icelandic with our historical data. For Danish we use the data available from KorpusDK, particularly from Korpus 2000 with 30 million to- 
kens. ${ }^{1}$ In that corpus the relative frequency of indefinite articles (en/et) per 10oo tokens is 25.61. In Old Danish, as indicated in Table 23, the relative frequency is much lower, with 9.31 indefinite articles per 1000 words. For Swedish we use the data available from one of the Språkbanken's corpora, the PAROLE corpus, which includes over 24 million tokens. ${ }^{2}$ The relative frequency of the indefinite articles (en/ett) in that corpus is 18.05 per 1000 tokens. In our Old Swedish material, the frequency is substantially lower and is very close to the frequency of indefinite articles in Old Danish, at 9.84 per 1000 tokens. Note that the relative frequencies in present-day Danish and Swedish differ greatly from each other, indicating that Danish uses indefinite articles more frequently than Swedish. For the Icelandic data we use The Tagged Icelandic Corpus (MÍM), which has 25 million tokens. ${ }^{3}$ Since present-day Icelandic does not have an indefinite article, the lexeme einn 'one' occurs in frequency lists as a numeral or as a pronoun (e.g., Imet one girl). Einn as a pronoun has a relative frequency of 0.48 per 1000 tokens, while the frequency of einn as a numeral is 1.48 per 1000 tokens. If these two are taken together, the frequency amounts to 1.96 per 1000 tokens, which is very close to the results for the Old Icelandic data, in which the frequency of the numeral einn is 2.07 per 1000 tokens. In sum, as expected, Icelandic does not reveal any substantial differences in the frequency of the numeral one. Old Swedish and Old Danish, on the other hand, differ from their present-day counterparts in that the frequency of indefinite articles has doubled in Swedish and almost tripled in Danish.

In the following sections we will study the correlations between the occurrence of either-IN or EN and major grammatical categories of the noun, such as number, case and gender, and semantic categories such as animacy, and finally between the occurrence of the incipient articles and syntactic roles.

\subsection{Definiteness and Number}

Modern North Germanic languages have all developed definite articles which may be used in both singular and plural NPs. The indefinite article, on the other hand (in all languages apart from Icelandic, which has not grammaticalized the

1 Source: https://ordnet.dk/korpusdk; Korpus 2000; 30 million tokens; accessed: 18/11/2019.

2 Source: https://spraakbanken.gu.se/korp/\#?lang=en\&stats_reduce=word\&cqp= ${ }_{55}$ B $\% 5$ D\&c orpus=parole; $P A R O L E ; 24,303,096$ tokens; accessed: 18/11/2019.

3 Source: http://www.malfong.is/index.php?lang=en\&pg=mim; 25 million tokens; accessed: $18 /$ $11 / 2019$. 
TABLE 24 Singular and plural nouns in the corpus (total frequencies)

\begin{tabular}{llrrrrrr}
\hline N & Number & \multicolumn{2}{c}{ Period I } & \multicolumn{2}{c}{ Period II } & \multicolumn{2}{c}{ Period III } \\
\hline \multirow{2}{*}{ Danish } & SG & 921 & $83.96 \%$ & 809 & $79.63 \%$ & 651 & $82.72 \%$ \\
& PL & 176 & $16.04 \%$ & 207 & $20.37 \%$ & 136 & $17.28 \%$ \\
& Total & 1,097 & $100.00 \%$ & 1,016 & $100.00 \%$ & 787 & $100.00 \%$ \\
Swedish & SG & 938 & $78.56 \%$ & 891 & $81.52 \%$ & 516 & $81.26 \%$ \\
& PL & 256 & $21.44 \%$ & 202 & $18.48 \%$ & 119 & $18.74 \%$ \\
& Ictal & 1,194 & $100.00 \%$ & 1,093 & $100.00 \%$ & 635 & $100.00 \%$ \\
& SG & 1182 & $76.95 \%$ & 740 & $71.36 \%$ & 488 & $75.31 \%$ \\
& PL & 354 & $23.05 \%$ & 297 & $28.64 \%$ & 160 & $24.69 \%$ \\
& Total & 1,536 & $100.00 \%$ & 1,037 & $100.00 \%$ & 648 & $100.00 \%$ \\
& & & & & & & \\
\end{tabular}

indefinite at all), has grammaticalized only in the singular, unlike in languages such as Spanish where plural indefinites are also morphologically marked.

The lack of a plural indefinite article is a natural consequence of the fact that the article's etymology is the numeral 'one', by definition difficult to combine with a plural noun. The numeral needs to be fully grammaticalized in the indefinite article function to be used with plural referents.

We would expect the overall proportions between the numbers to remain constant in each language, irrespective of the period chosen. The results presented in Table 24 confirm these expectations, revealing that the percentage of singular nouns among all nouns oscillates around $80 \%$ and that of plural nouns around $20 \%$ in all languages in our study, in all periods. The Icelandic data exhibit a certain difference from the other languages, in that the percentage of plural nouns is on average higher. In general, considering the whole dataset, $78.91 \%$ of all noun phrases in the corpora are singular, while $21.09 \%$ are plural.

The percentages for the suffixed definite article-IN (see Table 25) are slightly higher for SG for all languages in all periods, and slightly lower for PL for all languages and in all periods, in comparison with the overall results. This is hardly surprising, since the modern North Germanic languages allow bare plurals, and the use of the definite article with plural referents is subject to the additional criterion of inclusiveness, or in Hawkins' terms, totality. As Hawkins discusses at length, the felicitous use of the definite article with plural count nouns and mass nouns requires that the speaker refer to the totality of the objects, e.g., the tables is equivalent to all the tables and the water to all the water in the relevant shared set. "If the speaker refers to less than this totality [...] the hearer 
TABLE 25 Singular and plural nouns with -IN

\begin{tabular}{|c|c|c|c|c|c|c|c|}
\hline \multirow{2}{*}{$\begin{array}{l}\text {-IN } \\
\text { Danish }\end{array}$} & \multirow{2}{*}{$\begin{array}{l}\text { Number } \\
\text { SG }\end{array}$} & \multicolumn{2}{|c|}{ Period I } & \multicolumn{2}{|c|}{ Period II } & \multicolumn{2}{|c|}{ Period III } \\
\hline & & 63 & $94.03 \%$ & 120 & $86.33 \%$ & 134 & $93 \cdot 71 \%$ \\
\hline & PL & 4 & $5.97 \%$ & 19 & $13.67 \%$ & 9 & $6.29 \%$ \\
\hline & Total & 67 & $100.00 \%$ & 139 & $100.00 \%$ & 143 & $100.00 \%$ \\
\hline \multirow[t]{3}{*}{ Swedish } & $\mathrm{SG}$ & 90 & $95 \cdot 74 \%$ & 266 & $90.48 \%$ & 97 & $90.65 \%$ \\
\hline & PL & 4 & $4.26 \%$ & 28 & $9 \cdot 5^{2} \%$ & 10 & $9 \cdot 35 \%$ \\
\hline & Total & 94 & $100.00 \%$ & 294 & $100.00 \%$ & 107 & $100.00 \%$ \\
\hline \multirow[t]{3}{*}{ Icelandic } & SG & 129 & $82.17 \%$ & 79 & $86.81 \%$ & 78 & $95.12 \%$ \\
\hline & PL & 28 & $17.83 \%$ & 12 & $13.19 \%$ & 4 & $4.88 \%$ \\
\hline & Total & 157 & $100.00 \%$ & 97 & $100.00 \%$ & 82 & $100.00 \%$ \\
\hline
\end{tabular}

objects" (Hawkins 1978:159). Thus, the use of the definite article with plurals is motivated by other factors than referent identifiability.

We can further note that -IN is least likely to be used with a plural referent in Period I in both Danish and Swedish, but also in Period III in Icelandic. The use of plural definites is highest in Period II in both Danish and Swedish and in Period I in Icelandic. We do not find EN with plural referents; as mentioned above the plural indefinite article has not developed at all in North Germanic.

Finally, we should note that there is at least one reason why we would not expect definite NPs to contain significantly different percentages of singular and plural nouns than those found in the overall data. It has been noted in the literature that number distinctions may be limited to nouns high in the animacy hierarchy or that there may be splits lower in the hierarchy (SmithStark 1974, Corbett 2000). Considering the plurality markings on the noun, Corbett cites English as an example of such a split, where abstract inanimates such as friendliness are unlikely to appear in the plural, as opposed to concrete inanimates such as table (Corbett 2000:66). A similar split applies in North Germanic, where more abstract inanimates often lack plural forms (e.g., vänlighet 'friendliness'). However, in contrast to English, these abstract inanimates easily take a definite form, e.g., vänligheten 'the friendliness'. In other words, the fact that there are abstract nouns in the corpus would influence the results in a language such as English, where these do not appear in the plural and do not (usually) take the definite article. In North Germanic abstract nouns take the definite article as concrete ones do, hence the higher percentage for singular definites in our results. We will return to the animacy hierarchy in section 4.7. 


\subsection{Definiteness and Gender}

In all of the languages studied here the category of gender had three values in the studied periods, identical with those of Proto-Indo-European: masculine, feminine and neuter. In the Continental languages Danish and Swedish (and in some varieties of Norwegian Bokmål) the category has since been reduced to two values only: the so-called utrum, which came about through coalescence of the former masculine and feminine, and neutrum, which is a continuation of the original neuter gender. This change did not begin until the 16th century and was first noticeable in legal and official prose, while religious prose, being more conservative in this aspect, maintained the masculine-feminine distinction longer than other genres (Davidson 1990). Some Swedish dialects have retained the tripartite gender and even in standard language it is not impossible to use the pronoun hon 'she' with inanimate referent, but this use is restricted to a handful of nouns, e.g., klocka 'clock' in Vad är klockan? Hon är tre. 'What time is it? (lit. How much is the clock) She is three'. The process of gender reduction most likely originated in the pronominal paradigm (ibid.). Since the evolution of gender marking is of later date than the formation of the articles and falls well beyond the scope of the present work, we will not delve into the process further; however, we shall highlight some of the important interdependencies between the categories of gender and definiteness, in particular with reference to their exponents.

Gender is an inherent quality of the noun, which needs to be learned and usually cannot be deduced from the form of the noun (although in some languages there may exist quite reliable ways of 'guessing' the word's gender based on its form, e.g., the ending - $a$ in Polish almost infallibly signals feminine gender). However, for other nominals it is an inflectional category. Both demonstratives and the numeral 'one', i.e., the etymological sources of articles, are inflected for gender. In this sense they may become exponents of this category, similarly as they are exponents of number and case.

The diachrony of gender reduction in North Germanic is as yet understudied. Davidson (1990) studies the development in Swedish, but the study is limited to the process of change in the pronominal paradigm only, i.e., the replacement of the original pronouns han 'he' and hon 'she', originally used as anaphoric pronouns for all nouns irrespective of their animacy (in Modern Swedish their use is limited to human referents), by the pronoun den 'it.UTR', in analogy to det 'it.s', used as an anaphoric pronoun for nouns of neuter gender.

Davidson does not research other pronouns or agreement phenomena, which means that the picture of gender reduction is not fully clear. However, 
TABLE 26 The inflectional paradigm of the demonstrative hinn 'yon' in the singular

\begin{tabular}{llll}
\hline Hinn & M & F & N \\
\hline NOM & hinn & hin & hit \\
ACC & hin & hina & hit \\
DAT & hinum & hinni & hinu \\
GEN & hins & hinnar & hins \\
\hline
\end{tabular}

TABLE 27 The inflectional paradigm of the numeral enn 'one'

\begin{tabular}{llll}
\hline Enn & M & F & N \\
\hline NOM & enn & en & ett \\
ACC & enn & ena & ett \\
DAT & enom & enne & enom \\
GEN & ens & enna & ens \\
\hline
\end{tabular}

considering the forms relevant to our study, we may observe that the masculine and feminine distinction relied on case distinctions (the paradigms differ in each case) and that the masculine and feminine forms in the nominative were more similar to each other than either of them was to the neuter det or ett. Evidently, there were formal grounds for gender reduction, such as the similarity of masculine and feminine forms in the demonstrative paradigm and the loss of case, which in turn led to fewer distinctions between masculine and feminine words. It should be noted, however, that despite these formal premises, the process of gender system reduction may have been facilitated by semantic similarities between masculine and feminine classes, i.e., the higher proportion of nouns denoting animate, and in particular, human referents than in the neuter gender. Animacy seems to be the driving force of many changes in nominal categories in North Germanic.

The results for all of the NPs in the corpus (see Table 28) reveal that nouns of the masculine gender constitute on average $48 \%$ of all nouns, while the feminine and the neuter genders constitute on average around $25 \%$ each. Although it is natural that some genders may form larger classes, with more constituents 
TABLE 28 The proportions of all genders in the corpus

\begin{tabular}{llrrrrrr}
\hline N & Gender & \multicolumn{2}{c}{ Period I } & \multicolumn{2}{c}{ Period II } & \multicolumn{2}{c}{ Period III } \\
\hline Danish & M & 502 & $45.76 \%$ & 514 & $50.59 \%$ & 380 & $48.28 \%$ \\
& F & 297 & $27.07 \%$ & 247 & $24.31 \%$ & 242 & $30.75 \%$ \\
& $\mathrm{~N}$ & 298 & $27.16 \%$ & 255 & $25.10 \%$ & 165 & $20.97 \%$ \\
& Total & 1,097 & $100.00 \%$ & 1,016 & $100.00 \%$ & 787 & $100.00 \%$ \\
Icelandic & M & 520 & $43.55 \%$ & 520 & $47.58 \%$ & 263 & $41.42 \%$ \\
& M & 341 & $28.56 \%$ & 320 & $29.28 \%$ & 174 & $27.40 \%$ \\
& F & 333 & $27.89 \%$ & 253 & $23.14 \%$ & 198 & $31.18 \%$ \\
& F & 744 & $48.44 \%$ & 525 & $50.62 \%$ & 355 & $54.78 \%$ \\
& N & 471 & $24.15 \%$ & 256 & $24.69 \%$ & 136 & $20.99 \%$ \\
& Total & 1,536 & $100.00 \%$ & 1,037 & $100.00 \%$ & 648 & $100.00 \%$ \\
\hline
\end{tabular}

than others, the results do not necessarily indicate that this is the case in North Germanic. The results reported are the token and not the type frequencies; thus, out of all of the nouns in the corpus ca. $48 \%$ are masculine. However, it is possible that this number is a result of the fact that some high-frequency nouns (like 'king', 'bishop', 'knight', 'god') are masculine. In fact, the data available would suggest that it was the feminine nouns that constituted the largest group when type and not token is considered, at least in Swedish (Davidson 1990:88-89). On the other hand, earlier researchers on gender in Swedish report intuitions that it is the masculine gender that is the most frequent (Tegnér 1962 [1892]:135, Andersson 1979:44); since the authors do not quote any quantitative studies, we may conclude that their impression was formed by the abundance of masculine referents in the texts. Davidson claims further that concrete nouns are more often masculine, and abstract ones feminine (Davidson 1990:89), which may also explain some differences between genres in terms of the frequency of masculine and feminine nouns. Our observation is that the masculine nouns found in the texts denote humans more often than the feminine nouns do.

\subsubsection{Results by Gender}

In the following we report the results regarding definite and indefinite nominal phrases for each gender separately, beginning with the masculine gender. In the following tables we compare the frequency of the given gender among 
TABLE 29 Definiteness and the masculine gender

\begin{tabular}{llllllll}
\hline \multirow{2}{*}{ Masculine } & \multirow{2}{*}{ Context } & \multicolumn{2}{c}{ Period I } & \multicolumn{2}{c}{ Period II } & \multicolumn{2}{c}{ Period III } \\
\hline \multirow{2}{*}{ Danish } & M / N & $502 / 1,097$ & $45.76 \%$ & $514 / 1,016$ & $50.59 \%$ & $380 / 787$ & $48.28 \%$ \\
& M / -IN & $43 / 67$ & $64.18 \%$ & $77 / 139$ & $55.40 \%$ & $87 / 143$ & $60.84 \%$ \\
\multirow{2}{*}{ Swedish } & M / N & $520 / 1,194$ & $43.55 \%$ & $520 / 1,093$ & $47.58 \%$ & $263 / 635$ & $41.42 \%$ \\
& M / -IN & $57 / 94$ & $60.64 \%$ & $158 / 294$ & $53.74 \%$ & $46 / 107$ & $42.99 \%$ \\
Icelandic & M / N & $744 / 1,536$ & $48.44 \%$ & $525 / 1,037$ & $50.62 \%$ & $355 / 648$ & $54.78 \%$ \\
& M / -IN & $60 / 157$ & $38.22 \%$ & $42 / 91$ & $46.15 \%$ & $48 / 82$ & $58.54 \%$
\end{tabular}

TABLE 30 Indefiniteness and the masculine gender

\begin{tabular}{llllllll}
\hline \multirow{2}{*}{ Masculine } & \multirow{2}{*}{ Context } & \multicolumn{2}{c}{ Period I } & \multicolumn{2}{c}{ Period II } & \multicolumn{2}{c}{ Period III } \\
\hline \multirow{2}{*}{ Danish } & M / N & $502 / 1,097$ & $45.76 \%$ & $514 / 1,016$ & $50.59 \%$ & $380 / 787$ & $48.28 \%$ \\
& M / EN & $5 / 16$ & $31.25 \%$ & $38 / 78$ & $48.72 \%$ & $29 / 53$ & $54.72 \%$ \\
\multirow{3}{*}{ Swedish } & M / N & $520 / 1,194$ & $43.55 \%$ & $520 / 1,093$ & $47.58 \%$ & $263 / 635$ & $41.42 \%$ \\
& M / EN & $11 / 24$ & $45.83 \%$ & $40 / 70$ & $57.14 \%$ & $24 / 49$ & $48.98 \%$ \\
Icelandic & M / N & $744 / 1,536$ & $48.44 \%$ & $525 / 1,037$ & $50.62 \%$ & $355 / 648$ & $54.78 \%$ \\
& M / EN & $8 / 14$ & $57.14 \%$ & $12 / 21$ & $57.14 \%$ & $5 / 7$ & $71.43 \%$ \\
\hline
\end{tabular}

all of the nouns in the dataset $(\mathrm{N})$ and among the nouns in definite (-IN) or indefinite (EN) form.

Masculine nouns (see Table 29) are better represented in definite NPs in both Danish and Swedish throughout the three periods, albeit in Swedish in Period III the values are similar. In Period I in both Danish and Swedish the proportion of definite masculine nouns is higher by ca. $40 \%$ than the overall proportion of masculine nouns. In Period II the difference is around $10 \%$ for both languages. In Period III Danish and Swedish diverge; in Danish the frequency of definite masculine nouns is $27 \%$ higher than the overall proportion, while in Swedish it is higher by only $4.5 \%$. In Icelandic the values are quite similar throughout the three periods.

Similarly, masculine nouns constitute a large proportion of the indefinite NPs (see Table 30), especially in Icelandic in all three periods, but on the whole the results do not form a uniform pattern. The Icelandic results can be explained by the fact that EN, if not used purely as a numeral, was used as a presentative marker introducing salient new referents. 


\begin{tabular}{llllllll} 
Feminine & Context & \multicolumn{2}{c}{ Period I } & \multicolumn{2}{c}{ Period II } & \multicolumn{2}{c}{ Period III } \\
\hline \multirow{2}{*}{ Danish } & F / N & $297 / 1,097$ & $27.07 \%$ & $247 / 1,016$ & $24.31 \%$ & $242 / 787$ & $30.75 \%$ \\
& F / IN & $10 / 67$ & $14.93 \%$ & $25 / 139$ & $17.99 \%$ & $23 / 143$ & $16.08 \%$ \\
Swedish & F / N & $341 / 1,194$ & $28.56 \%$ & $320 / 1,093$ & $29.28 \%$ & $174 / 635$ & $27.40 \%$ \\
& F / -IN & $19 / 94$ & $20.21 \%$ & $83 / 294$ & $28.23 \%$ & $32 / 107$ & $29.91 \%$ \\
Icelandic & F / N & $371 / 1,536$ & $24.15 \%$ & $256 / 1,037$ & $24.69 \%$ & $136 / 648$ & $20.99 \%$ \\
& F / IN & $44 / 157$ & $28.03 \%$ & $23 / 91$ & $25.27 \%$ & $19 / 82$ & $23.17 \%$
\end{tabular}

(124) Grím-ur hét einn bónd-i, mikils hátt-ar

Grim-NOM was.called EN yeoman-NOM very important-NOM og vel fjáreigand-i.

and well wealthy-Nom

'Grim was called a yeoman, important and rich.' (IS_Jart, Period I)

The noun most frequently used in this construction was maðr 'man', a masculine noun.

The results for the feminine gender (see Table 31) are quite different from those for masculine nouns. The feminine nouns are heavily under-represented in defNPs in Danish in all periods. In Period I and III the proportion of feminine definite nouns is smaller by almost $50 \%$ than the overall proportion of feminine nouns, and in Period II the difference is ca. $25 \%$. In Swedish feminine defNPs are strongly under-represented only in Period I, where the difference between the results for $\mathrm{N}$ and -IN amounts to $28 \%$. In Periods II and III the results are similar. In Icelandic, on the other hand, feminine nouns are better represented in definite nominal phrases throughout all of the periods.

In the case of the frequency of feminine nouns in indefinite nominal phrases (see Table 32), none of the languages exhibits any clear patterns. In Danish in Periods I and II the proportions are very close, while in Period III feminine indefinite NPs are strongly under-represented, i.e., there is a difference of $20 \%$ between the results for $\mathrm{N}$ and EN. In Swedish feminine indefinite NPs are very strongly represented in the first period, but heavily under-represented in the following periods. We observe a reverse tendency in Icelandic, where feminine indefinite NPs are under-represented in Period I, but in Periods II and III the proportion is higher by $36 \%$ than the proportion of feminine nouns overall. However, the overall number of instances of EN is very low in Icelandic so the results are not statistically significant. 
TABLE 32 Indefiniteness and the feminine gender

\begin{tabular}{llllllll}
\hline \multirow{2}{*}{ Feminine } & Context & \multicolumn{2}{c}{ Period I } & \multicolumn{2}{c}{ Period II } & \multicolumn{2}{c}{ Period III } \\
\hline \multirow{2}{*}{ Danish } & F / N & $297 / 1,097$ & $27.07 \%$ & $247 / 1,016$ & $24.31 \%$ & $242 / 787$ & $30.75 \%$ \\
& F / EN & $4 / 16$ & $25.00 \%$ & $20 / 78$ & $25.64 \%$ & $13 / 53$ & $24.53 \%$ \\
\multirow{3}{*}{ Swedish } & F / N & $341 / 1,194$ & $28.56 \%$ & $320 / 1,093$ & $29.28 \%$ & $174 / 635$ & $27.40 \%$ \\
& F / EN & $9 / 24$ & $37.50 \%$ & $17 / 70$ & $24.29 \%$ & $8 / 49$ & $16.33 \%$ \\
Icelandic & F / N & $371 / 1,536$ & $24.15 \%$ & $256 / 1,037$ & $24.69 \%$ & $136 / 648$ & $20.99 \%$ \\
& F / EN & $3 / 14$ & $21.43 \%$ & $6 / 21$ & $28.57 \%$ & $2 / 7$ & $28.57 \%$ \\
& & & & & & &
\end{tabular}

TABLE 33 Definiteness and the neuter gender

\begin{tabular}{llllllll}
\hline Neuter & \multirow{2}{*}{ Context } & \multicolumn{2}{c}{ Period I } & \multicolumn{2}{c}{ Period II } & \multicolumn{2}{c}{ Period III } \\
\hline \multirow{2}{*}{ Danish } & $\mathrm{Ne} / \mathrm{N}$ & $298 / 1,097$ & $27.16 \%$ & $255 / 1,016$ & $25.10 \%$ & $165 / 787$ & $20.97 \%$ \\
& $\mathrm{Ne} /-\mathrm{IN}$ & $14 / 67$ & $20.90 \%$ & $38 / 139$ & $27.34 \%$ & $33 / 143$ & $23.08 \%$ \\
\multirow{3}{*}{ Swedish } & $\mathrm{Ne} / \mathrm{N}$ & $333 / 1,194$ & $27.89 \%$ & $253 / 1,093$ & $23.14 \%$ & $198 / 635$ & $31.18 \%$ \\
& $\mathrm{Ne} /-\mathrm{IN}$ & $17 / 94$ & $18.09 \%$ & $54 / 294$ & $18.37 \%$ & $29 / 107$ & $27.10 \%$ \\
\multirow{2}{*}{ Icelandic } & $\mathrm{Ne} / \mathrm{N}$ & $421 / 1,536$ & $27.41 \%$ & $256 / 1,037$ & $24.69 \%$ & $157 / 648$ & $24.23 \%$ \\
& $\mathrm{Ne} /-\mathrm{IN}$ & $51 / 157$ & $32.48 \%$ & $26 / 91$ & $28.57 \%$ & $14 / 82$ & $17.07 \%$ \\
\hline
\end{tabular}

The neuter gender is in general under-represented in definite NPs compared with all NPs (see Table 33); the results are very similar to those for the feminine. Even though in Danish in Periods II and III and in Icelandic in Periods I and II neuter definite NPs are better represented, the differences here are not substantial, being no higher than $20 \%$.

Again, in the case of indefinite NPs no clear patterns are revealed (see Table 34). In the Icelandic data neuter NPs with an indefinite article, or in many cases a numeral, are heavily under-represented. In the Danish and Swedish data there are no considerable differences between the proportions, with two exceptions: in Danish in Period I the proportion of neuter indefinite NPs is ca. 6o\% higher than the overall proportion, while in Swedish in the same period the proportion of neuter indefinite NPs is ca. $55 \%$ lower than the overall proportion.

Overall, the results indicate that, as expected, definite and indefinite expression in the periods studied is not essentially linked to grammatical gender, but rather to the type of referents that are expressed through nouns with a partic- 
TABLE 34 Indefiniteness and the neuter gender

\begin{tabular}{|c|c|c|c|c|c|c|c|}
\hline \multirow{2}{*}{$\begin{array}{l}\text { Neuter } \\
\text { Danish }\end{array}$} & \multirow{2}{*}{$\begin{array}{l}\text { Context } \\
\mathrm{Ne} / \mathrm{N}\end{array}$} & \multicolumn{2}{|c|}{ Period I } & \multicolumn{2}{|c|}{ Period II } & \multicolumn{2}{|c|}{ Period III } \\
\hline & & 298 / 1,097 & $27.16 \%$ & $255 / 1,016$ & $25.10 \%$ & $165 / 787$ & $20.97 \%$ \\
\hline & $\mathrm{Ne} / \mathrm{EN}$ & $7 / 16$ & $43.75 \%$ & $19 / 78$ & $24.36 \%$ & $11 / 53$ & $20.75 \%$ \\
\hline \multirow[t]{2}{*}{ Swedish } & $\mathrm{Ne} / \mathrm{N}$ & 333 / 1,194 & $27.89 \%$ & 253 / 1,093 & $23.14 \%$ & $198 / 635$ & $31.18 \%$ \\
\hline & $\mathrm{Ne} / \mathrm{EN}$ & $3 / 24$ & $12.50 \%$ & $12 / 70$ & $17.14 \%$ & $17 / 49$ & $34.69 \%$ \\
\hline \multirow[t]{2}{*}{ Icelandic } & $\mathrm{Ne} / \mathrm{N}$ & $421 / 1,536$ & $27.41 \%$ & $256 / 1,037$ & $24.69 \%$ & $157 / 648$ & $24.23 \%$ \\
\hline & $\mathrm{Ne} / \mathrm{EN}$ & $2 / 14$ & $14.29 \%$ & $1 / 21$ & $4.76 \%$ & $0 / 7$ & $0.00 \%$ \\
\hline
\end{tabular}

ular gender. If there are pragmatic factors at play, and the definite form is used primarily with important discourse referents before it is used with all semantically definite referents, this would explain the difference between the definite marking of masculine nouns, on the one hand, and feminine and neuter nouns, on the other. The masculine class includes many animate, human nouns, which are very often sentence subjects and/or topics. The neuter class includes very few animate and next to no human nouns, and nouns from this class typically appear in sentences as objects (or prepositional objects). This would explain why there are proportionally more masculine nouns among the definites than there are neuters, assuming that the definite article is strongly connected with the role of subject or topic, at least at the early stages of grammaticalization. Another category which correlates, more strongly, with subjecthood and topicality is case, which will be discussed in the next section.

\subsection{Definiteness and Case}

During the period of article grammaticalization other grammatical categories undergo changes as well. The most spectacular is the decline of case in the Continental North Germanic languages, Danish and Swedish (and in Norwegian, which is not studied here). The reduction of case proceeds for more than 200 years (see Norde 1997, Skrzypek 2005, Delsing 2014) and partly overlaps with the rise of the definite and indefinite articles.

The two processes - the decline of case and the development of definiteness-have taken place in other Indo-European languages in the course of their history, for example, in some Germanic languages like English and Dutch, in the Romance languages French, Spanish and Italian, and in two Slavic languages, Bulgarian and Macedonian. At the same time the case system is more 
or less intact in Icelandic and Faroese and reduced but still present in German, all three languages having developed definite articles. The case system is preserved in most Slavic languages (apart from Bulgarian and Macedonian), while no definite or indefinite articles have developed in these languages (though see Dvorak 2019 on possible early stages of definite article grammaticalization in Czech). In other words, it does not seem that there is a straightforward interdependency between loss of case and rise of definiteness. In fact, diachronic research into the loss of dative case in Swedish suggests that the rise of the definite article in that language had a temporary conserving effect on the case system (Skrzypek 2005). It is also to be noted that the case distinctions preserved in German are found mainly on determiners, including definite and indefinite articles, while the noun paradigms exhibit little inflection (Harbert 2006). In this sense, the two categories of case and definiteness interact, in that they are encoded together on the same formative (see also Lyons C. 1999:199).

In languages beyond Indo-European other types of interdependencies may be observed. One is the restriction of certain case markers to definite noun phrases. For example, the accusative case may be marked morphologically only on definite objects, as in Turkish (see Lyons C. 1999:201 and references therein).

The reduction of case was not a process with a uniform history in all North Germanic languages. Firstly, it has not taken place at all in the Insular languages Icelandic and Faroese. Secondly, it seems to have originated in Danish and spread from the southern boundaries of Scandinavia to the north, with Danish at the fore of the change and Swedish and Norwegian following later on. Although it has long been claimed that a major force behind case reduction was language contact with Low German, it has since been demonstrated that while such contact could in fact have been a catalyst of the change, the change was initiated before the contact ever took place (see especially Ringgaard 1986, Norde 1997, Skrzypek 2005).

The loss of case is best documented in Swedish sources, since in Danish the system becomes undermined before the first texts are written. In Norwegian the loss of case comes so late that it cannot be studied in actual texts, since at the time of case reduction Norwegian was no longer the written standard in Norway and there are hardly any extant Norwegian texts (Delsing 2014:27). The reduction comprised two major phases: the first was the reduction of case endings resulting in growing syncretism of forms (paradigmatic change), while the second consisted of a limited use of marked cases in certain constructions, which instead favoured unmarked forms with zero endings, such as the accusative and (later) the nominative (syntagmatic change; see Delsing 2014:28). Although the paradigmatic change was the first stage of the decline of 
TABLE 35 Example declination of weak nouns: bondi 'yeoman' and kirkja 'church'a

\begin{tabular}{lllll}
\hline & bondi & bondi-DEF & kirkja & kirkja-DEF \\
\hline NOM & bondi & bondin & kirkja & kirkjan \\
ACC & bonda & bondan & kirkju & kirkjuna \\
DAT & bonda & bondanom & kirkju & kirkjunni \\
GEN & bonda & bondans & kirkju & kirkjunnar \\
English & yeoman & the yeoman & church & the church \\
\hline
\end{tabular}

a Bare nouns with weak endings such as bond- $a$ and kirkj- $u$ in Table 35 are annotated as oblique case (OBL) in the corpus, the leftmost column in Table 35 lists the cases as they apply to the definite-marked forms of these nouns.

the case system in Danish and Swedish, the syntagmatic changes partly coincided with it; in Danish from 1200 onwards, in Swedish from ca. 1300 and later.

It should be noted here that the rise of the definite article had, to some extent, a petrifying effect on case. Because the definite article retained its own case inflection after it was cliticized onto the noun, in some instances the case of the noun would be clarified. This is clearly discernible with weak masculine nouns such as bondi 'yeoman' (forms from Old Swedish) or most feminine nouns, such as kirkja 'church' (forms from Modern Icelandic), as presented in Table 35 .

Table 36 presents an overview of the frequencies of all of the noun case forms in the corpus.

The results illustrate a number of important facts. Firstly, we observe that case reduction in Danish is of very early date. Only ca. $13 \%$ of nouns in Period II and ca. $9 \%$ in Period III could be tagged with any certainty as NOM, ACC, DAT or GEN, the majority of them representing the genitive, the case of which a remnant (the so-called s-genitive) is found in Modern Danish (and Modern Swedish); see in particular Norde (1997). Over $86 \%$ and $90 \%$ of nouns in Periods II and III respectively were tagged as NO-END, as there was no ending and no other information to indicate their case form.

The Swedish results are similar to those for Danish, but it is clear that the case reduction is of later date. Periods I and II exhibit very similar results, but a slump occurs in Period III, where over $80 \%$ of the nouns could be tagged only as NO-END. The fact that there was such a difference in the time of case reduction between Danish and Swedish has been noted in the literature; see in particular Ringgaard (1986). 
TABLE 36 Proportions of cases in the corpus

\begin{tabular}{|c|c|c|c|c|c|c|c|}
\hline \multirow{2}{*}{$\begin{array}{l}\mathbf{N} \\
\text { Danish }\end{array}$} & \multirow{2}{*}{$\begin{array}{l}\text { Case } \\
\mathrm{NOM}\end{array}$} & \multicolumn{2}{|c|}{ Period I } & \multicolumn{2}{|c|}{ Period II } & \multicolumn{2}{|c|}{ Period III } \\
\hline & & 281 & $25.62 \%$ & 5 & $0.49 \%$ & $\mathrm{O}$ & $0.00 \%$ \\
\hline & $\mathrm{ACC}$ & 421 & $38.38 \%$ & 27 & $2.66 \%$ & $\mathrm{O}$ & $0.00 \%$ \\
\hline & DAT & 59 & $5 \cdot 38 \%$ & 3 & $0.30 \%$ & o & $0.00 \%$ \\
\hline & GEN & 89 & $8.11 \%$ & 48 & $4.72 \%$ & 59 & $7 \cdot 50 \%$ \\
\hline & $\mathrm{OBL}$ & 128 & $11.67 \%$ & 54 & $5 \cdot 31 \%$ & 12 & $1.5^{2} \%$ \\
\hline & No ending & 119 & $10.85 \%$ & 879 & $86.5^{2} \%$ & 716 & $90.98 \%$ \\
\hline & Total & 1,097 & $100.00 \%$ & 1,016 & $100.00 \%$ & 787 & $100.00 \%$ \\
\hline \multirow[t]{7}{*}{ Swedish } & NOM & 315 & $26.38 \%$ & 284 & $25.98 \%$ & 13 & $2.05 \%$ \\
\hline & ACC & 388 & $32.50 \%$ & 429 & $39.25 \%$ & 15 & $2.36 \%$ \\
\hline & DAT & 180 & $15.07 \%$ & 171 & $15.65 \%$ & 37 & $5.83 \%$ \\
\hline & GEN & 153 & $12.81 \%$ & 98 & $8.97 \%$ & 49 & $7 \cdot 72 \%$ \\
\hline & OBL & 76 & $6.37 \%$ & $5^{6}$ & $5.12 \%$ & 5 & $0.79 \%$ \\
\hline & No ending & 82 & $6.87 \%$ & 55 & $5.03 \%$ & $5^{16}$ & $81.26 \%$ \\
\hline & Total & 1,194 & $100.00 \%$ & 1,093 & $100.00 \%$ & 635 & $100.00 \%$ \\
\hline \multirow[t]{7}{*}{ Icelandic } & NOM & 454 & $29.56 \%$ & 288 & $27.77 \%$ & 181 & $27.93 \%$ \\
\hline & ACC & 423 & $27 \cdot 54 \%$ & 345 & $33.27 \%$ & 212 & $32.72 \%$ \\
\hline & DAT & 348 & $22.66 \%$ & 245 & $23.63 \%$ & 124 & $19.14 \%$ \\
\hline & GEN & 205 & $13.35 \%$ & 108 & $10.41 \%$ & 95 & $14.66 \%$ \\
\hline & $\mathrm{OBL}$ & 103 & $6.71 \%$ & $5^{\circ}$ & $4.82 \%$ & 35 & $5.40 \%$ \\
\hline & No ending & 3 & $0.19 \%$ & 1 & $0.10 \%$ & 1 & $0.15 \%$ \\
\hline & Total & 1,536 & $100.00 \%$ & 1,037 & $100.00 \%$ & 648 & $100.00 \%$ \\
\hline
\end{tabular}

The Icelandic case system, on the other hand, remains intact; the nouns annotated as NO-END are indeclinable words, e.g., frendsemi 'relationship, kinship', and constitute about $0.15 \%$ of all nouns. The proportions between all cases remain the same in all three periods, which may be understood in terms of the original cases retaining their functions, but any interpretation of the results would need a more in-depth study. Finally recall that the Danish and Swedish case systems are reduced through two types of change: the growing syncretism of forms and the loss of case marking.

\subsubsection{Case and the Definite Article}

Even though there is no compelling evidence for interdependencies between the loss of case and the emergence of definiteness marking, there are enough tendencies to assume that there will be some degree of correspondence be- 
tween the two processes. Not least because grammatical cases often overlap with particular functions, such as subject or object, which in turn differ with respect to definiteness (see 4.6). One should, however, proceed with caution positing a simple scenario, in which the dwindling case system makes way for definiteness marking, as the North Germanic languages differ among themselves with respect to the category of case (see in particular Barðdal 2001 and 2009).

In this section, we will examine the case forms that appear earliest as definites, without considering roles in sentences, which will be the topic of the next section. Table 37 illustrates the distribution of all of the suffixed definite forms (-IN) in the corpus between the case forms. The results are not separated into SG and PL.

The results presented in Table 37 are to be analysed in the context of the overall results in Table 36 (section 4.5). We noted that nouns that were unequivocally NOM are found in Danish in Period I ( $25.62 \%$ of all nouns), but they are virtually non-existent in Periods II and III. We therefore cannot expect to find any defNPs in the nominative in Periods II and III, because we have no endings to tell us that that is the case. Similarly, the lower frequency of NOM in Swedish in Period III is not to be understood as implying the fact that nouns in NOM no longer appear as definite, but rather that the NOM ending is now lost on virtually all nouns. They appear instead in the results for nouns without any case endings.

We observe that the distribution of -IN between cases is quite consistent throughout the three periods in Icelandic, with lower results for GEN and DAT, but similar values for NOM and ACC. The grammatical roles of subject and object, which are strongly associated with these cases, will be discussed in the following section. Firstly, we compare the frequencies for all nouns and for those tagged as -IN only for each case separately, beginning with the nominative (see Table 38 ).

Compared with its overall frequency, the nominative is preferred in defNPs in Danish in Period I and in Swedish in both Period I and II, especially in the latter. It seems that while the overall frequency of the nominative remains unchanged in Swedish between Period I and II, the grammaticalizing definite article comes to be strongly associated with the nominative, and most likely with the function of subject (see section 4.6).

In Icelandic the values for all NPs and for defNPs are similar in Period I, but we observe a clear drop in the value for defNPs in Period II, something we would not expect in a language with a stable case system and relatively well-developed definite article. It seems therefore that even though the definite article may seem well-developed in Icelandic (at least in comparison with 
TABLE 37 Proportions of cases among definite NPs

\begin{tabular}{|c|c|c|c|c|c|c|c|}
\hline \multirow{2}{*}{$\begin{array}{l}\text {-IN } \\
\text { Danish }\end{array}$} & \multirow{2}{*}{$\begin{array}{l}\text { Case } \\
\text { NOM }\end{array}$} & \multicolumn{2}{|c|}{ Period I } & \multicolumn{2}{|c|}{ Period II } & \multicolumn{2}{|c|}{ Period III } \\
\hline & & 28 & $41.79 \%$ & $\mathrm{O}$ & $0.00 \%$ & $\mathrm{O}$ & $0.00 \%$ \\
\hline & $\mathrm{ACC}$ & 25 & $37 \cdot 31 \%$ & 7 & $5.04 \%$ & $\mathrm{O}$ & $0.00 \%$ \\
\hline & DAT & 1 & $1.49 \%$ & 2 & $1.44 \%$ & $\mathrm{O}$ & $0.00 \%$ \\
\hline & GEN & 12 & $17 \cdot 91 \%$ & 4 & $2.88 \%$ & 3 & $2.10 \%$ \\
\hline & OBL & $\mathrm{O}$ & $0.00 \%$ & 1 & $0.72 \%$ & $\mathrm{O}$ & $0.00 \%$ \\
\hline & No ending & 1 & $1.49 \%$ & 125 & $89.93 \%$ & 140 & $97.90 \%$ \\
\hline & Total & 67 & $100.00 \%$ & 139 & $100.00 \%$ & 143 & $100.00 \%$ \\
\hline \multirow[t]{7}{*}{ Swedish } & NOM & 31 & $32.98 \%$ & 134 & $45 \cdot 58 \%$ & 6 & $5.61 \%$ \\
\hline & ACC & 37 & $39.36 \%$ & 102 & $34.69 \%$ & 11 & $10.28 \%$ \\
\hline & DAT & 14 & $14.89 \%$ & 33 & $11.22 \%$ & 13 & $12.15 \%$ \\
\hline & GEN & 9 & $9.57 \%$ & 25 & $8.50 \%$ & 14 & $13.08 \%$ \\
\hline & OBL & 3 & $3.20 \%$ & $\mathrm{O}$ & $0.00 \%$ & 1 & $0.93 \%$ \\
\hline & No ending & o & $0.00 \%$ & $\mathrm{o}$ & $0.00 \%$ & 62 & $57.94 \%$ \\
\hline & Total & 94 & $100.00 \%$ & 294 & $100.00 \%$ & 107 & $100.00 \%$ \\
\hline \multirow[t]{7}{*}{ Icelandic } & NOM & 48 & $30.57 \%$ & 15 & $16.48 \%$ & 16 & $19.51 \%$ \\
\hline & ACC & 51 & $32.48 \%$ & 43 & $47.25 \%$ & 35 & $42.68 \%$ \\
\hline & DAT & 43 & $27.39 \%$ & 22 & $24.18 \%$ & 16 & $19.51 \%$ \\
\hline & GEN & 15 & $9.55 \%$ & 11 & $12.09 \%$ & 13 & $15.85 \%$ \\
\hline & OBL & $\mathrm{O}$ & $0.00 \%$ & o & $0.00 \%$ & 2 & $2.44 \%$ \\
\hline & No ending & o & $0.00 \%$ & o & $0.00 \%$ & $\mathrm{O}$ & $0.00 \%$ \\
\hline & Total & 157 & $100.00 \%$ & 91 & $100.00 \%$ & 82 & $100.00 \%$ \\
\hline
\end{tabular}

\begin{tabular}{|c|c|c|c|c|c|c|c|}
\hline \multirow{2}{*}{$\begin{array}{l}\text { NOM } \\
\text { Danish }\end{array}$} & \multirow{2}{*}{$\begin{array}{l}\text { Context } \\
\text { NOM / N }\end{array}$} & \multicolumn{2}{|c|}{ Period I } & \multicolumn{2}{|c|}{ Period II } & \multicolumn{2}{|c|}{ Period III } \\
\hline & & $281 / 1,097$ & $25.62 \%$ & $5 / 1,016$ & $0.49 \%$ & o / 787 & $0.00 \%$ \\
\hline & NOM / -IN & $28 / 67$ & $41.79 \%$ & o / 139 & $0.00 \%$ & o / 143 & $0.00 \%$ \\
\hline \multirow[t]{2}{*}{ Swedish } & $\mathrm{NOM} / \mathrm{N}$ & $315 / 1,194$ & $26.38 \%$ & $284 / 1,093$ & $25.98 \%$ & $13 / 635$ & $2.05 \%$ \\
\hline & NOM / -IN & $31 / 94$ & $32.98 \%$ & $134 / 294$ & $45 \cdot 58 \%$ & $6 / 107$ & $5.61 \%$ \\
\hline \multirow[t]{2}{*}{ Icelandic } & $\mathrm{NOM} / \mathrm{N}$ & $454 / 1,536$ & $29.56 \%$ & $288 / 1,037$ & $27.77 \%$ & $181 / 648$ & $27.93 \%$ \\
\hline & NOM / -IN & $48 / 157$ & $30.57 \%$ & $15 / 91$ & $16.48 \%$ & $16 / 82$ & $19.51 \%$ \\
\hline
\end{tabular}




\begin{tabular}{lllllllr} 
ACC & Context & \multicolumn{2}{c}{ Period I } & \multicolumn{2}{c}{ Period II } & \multicolumn{2}{c}{ Period III } \\
\hline \multirow{2}{*}{ Danish } & ACC / N & $421 / 1,097$ & $38.38 \%$ & $27 / 1,016$ & $2.66 \%$ & $0 / 787$ & $0.00 \%$ \\
& ACC / -IN & $25 / 67$ & $37.31 \%$ & $7 / 139$ & $5.04 \%$ & $0 / 143$ & $0.00 \%$ \\
Swedish & ACC / N & $388 / 1,194$ & $32.50 \%$ & $429 / 1,093$ & $39.25 \%$ & $15 / 635$ & $2.36 \%$ \\
& ACC / -IN & $37 / 94$ & $39.36 \%$ & $102 / 294$ & $34.69 \%$ & $11 / 107$ & $10.28 \%$ \\
Icelandic & ACC / N & $423 / 1,536$ & $27.54 \%$ & $345 / 1,037$ & $33.27 \%$ & $212 / 648$ & $32.72 \%$ \\
& ACC / -IN & $51 / 157$ & $32.48 \%$ & $43 / 91$ & $47.25 \%$ & $35 / 82$ & $42.68 \%$
\end{tabular}

Danish and Swedish), there are still some changes in its functions, which may be reflected in the proportions between the cases.

Interestingly enough, and in contrast to the results for the nominative, the results for the accusative (see Table 39) are similar for all NPs and for defNPs. This indicates that there was no preference for this case in definite contexts, but neither was it disfavoured. A significant difference in proportions is found in Icelandic in Period II (which was also the time when the values for NOM in defNPs dropped significantly below the values for all NPs) and Period III, as well as in Swedish in Period III. The latter difference can be explained by the fact that while the accusative was on the whole lost (the ending either reduced or coalesced with the ending for some other case) in the bare noun, it was retained in the definite form (the double inflection). Consider a neutral noun land 'country'. Originally, its paradigm consisted of three distinct forms: land (NOM/ACC), landi (DAT), lands (GEN). With the reduction of the case system the dative form was lost. However, even after that happened, the definite dative form could be found as land-i-n-o 'country-DAT-DEF-DAT'. With the accusative case, this effect is almost entirely limited to the plural forms, as the accusative and the nominative have coalesced at an earlier stage in most paradigms.

Definite NPs in the dative (see Table 40) are slightly preferred in Icelandic in Period I and in Swedish in Period III, but on the whole the values are similar for all NPs and for defNPs. As in the case of the accusative, the higher results in Swedish are again due to the preservation of the dative form in the definite, which is a result of the double inflection of the noun.

Similar to the results regarding the dative case, there is no clear preference for the genitive case in definite NPs (see Table 41), except in Danish in Period I and in Swedish in Period III. However, while we could explain the higher values for dative and accusative defNPs by double inflection, the situation is less straightforward with the genitive. It is a case whose formal representation is 
TABLE 40 The dative and definiteness

\begin{tabular}{lllrlrlr}
\hline \multirow{2}{*}{ DAT } & Context & \multicolumn{2}{c}{ Period I } & \multicolumn{2}{c}{ Period II } & \multicolumn{2}{c}{ Period III } \\
\hline \multirow{2}{*}{ Danish } & DAT / N & $59 / 1,097$ & $5 \cdot 38 \%$ & $3 / 1,016$ & $0.30 \%$ & $0 / 787$ & $0.00 \%$ \\
& DAT / IN & $1 / 67$ & $1.49 \%$ & $2 / 139$ & $1.44 \%$ & $0 / 143$ & $0.00 \%$ \\
\multirow{5}{*}{ Swedish } & DAT / N & $180 / 1,194$ & $15.07 \%$ & $171 / 1,039$ & $15.65 \%$ & $37 / 635$ & $5.83 \%$ \\
& DAT / -IN & $14 / 94$ & $14.89 \%$ & $33 / 294$ & $11.22 \%$ & $13 / 107$ & $12.15 \%$ \\
Icelandic & DAT / N & $348 / 1,536$ & $22.66 \%$ & $245 / 1,037$ & $23.63 \%$ & $124 / 648$ & $19.14 \%$ \\
& DAT / -IN & $43 / 157$ & $27.39 \%$ & $22 / 91$ & $24.18 \%$ & $16 / 82$ & $19.51 \%$ \\
& & & & & & & \\
\end{tabular}

TABLE 41 The genitive and definiteness

\begin{tabular}{lllrlllr}
\hline GEN & \multirow{2}{*}{ Context } & \multicolumn{2}{c}{ Period I } & \multicolumn{2}{c}{ Period II } & \multicolumn{2}{c}{ Period III } \\
\hline \multirow{2}{*}{ Danish } & GEN / N & $89 / 1,097$ & $8.11 \%$ & $48 / 1,016$ & $4.72 \%$ & $59 / 787$ & $7.50 \%$ \\
& GEN / -IN & $12 / 67$ & $17.91 \%$ & $4 / 139$ & $2.88 \%$ & $3 / 143$ & $2.10 \%$ \\
Swedish & GEN / N & $153 / 1,194$ & $12.81 \%$ & $98 / 1,093$ & $8.97 \%$ & $49 / 635$ & $7.72 \%$ \\
& GEN / -IN & $9 / 94$ & $9.57 \%$ & $25 / 294$ & $8.50 \%$ & $14 / 107$ & $13.08 \%$ \\
Icelandic & GEN / N & $205 / 1,536$ & $13.35 \%$ & $108 / 1,037$ & $10.41 \%$ & $95 / 648$ & $14.66 \%$ \\
& GEN / -IN & $15 / 157$ & $9.55 \%$ & $11 / 91$ & $12.09 \%$ & $13 / 82$ & $15.85 \%$ \\
\hline
\end{tabular}

preserved until today, in the so-called s-genitive, a phrasal marker used with possessor NPs (see Norde 1997 for a historical description and Börjars \& Harries 2008 for a modern discussion). It is important to remember, though, that while one of the original genitive endings was preserved and spread to all nouns, the use of the s-form was gradually limited to possessor NPs and no longer appeared in NPs governed by prepositions or verbs. The higher values in Swedish in Period III are mostly due to possessor NPs. As a recent study on present-day Swedish indicates, the s-genitive strongly prefers definite NPs and proper names, disfavouring indefinite NPs (Piotrowska 2020). This development towards explicitly definite possessor-NPs in the s-genitive is already discernible in Old Swedish and Old Danish, especially in Periods II and III, when we observe a surge of definite possessor NPs with the s-ending (Piotrowska, in press).

Of the four cases present in Period I in all three languages, only the nominative exhibits a correlation with definiteness. Percentage-wise the nominative accounts for a greater proportion among definite NPs than among the over- 
all number of nouns in Period I, in both Danish and Swedish. This correlation gradually weakens as the original case endings are lost and the definite article grammaticalized.

\subsubsection{Case and the Indefinite Article}

Table 42 gives the distribution of all indefinite forms (EN) in the corpus between the case forms. The results include only singular NPs, as there are no plural NPs in the corpus where EN would be used.

As was the case with the results in Table 37 (section 4.5.1), the results in the tables above reflect not only the use of definite or indefinite NPs in each case, but the fate of the cases as well. In the case of indefinite NPs (EN) presented in Table 42, we note that the case reduction proceeds fastest in Danish, and that by Period III only two noun forms are found in the texts: those in the genitive (or some remnant thereof) and those with no ending. We can further note that the grammaticalization of the indefinite article seems to have progressed furthest in Danish. As early as Period I indefNPs appear in ACC, as objects, which is the typical context for an indefinite NP, as it usually carries new information. The results for NOM, i.e., subjects, are considerably lower.

In Icelandic, on the other hand, the highest values are for NOM, in both Period I and III. This is understandable, since the most typical use of EN in Icelandic prose is to introduce new and salient referents, typically in some variant of the following sentence:

(125) Ein jungfrú er út í Myklagarð-i er heitir Ríkilað

EN maiden is out in Myklagarð-DAT which is.called Ríkilað.NOM 'There is a maiden out in Myklagarð who is called Ríkilað.' (IS_Jarl, Period III)

It is to be noted that the EN in these NPs is not really an indefinite article (which, as we have mentioned before, has not grammaticalized in Icelandic at all), but the original numeral 'one', used in a presentative function (see section 2.3), which is the first stage of the indefinite article's grammaticalization. Comparing the percentages in Table 42, it is also important to keep in mind that the Icelandic texts in the corpus have a relatively low frequency of EN, with 40 instances against 142 and 146 in Swedish and Danish respectively.

Swedish also exhibits some unexpected developments. The already high values for nominative indefNPs in Period I rise even further in Period II, reaching a peak of $42 \%$, only to drop to ca. $2 \%$ in Period III. The explanation is to be found in the history of the indefinite article in Swedish, which, like in other languages, begins with a presentative function, although, more specifically lim- 
TABLE 42 Proportions of cases among indefinite NPs

\begin{tabular}{|c|c|c|c|c|c|c|c|}
\hline \multirow{2}{*}{$\begin{array}{l}\text { EN } \\
\text { Danish }\end{array}$} & \multirow{2}{*}{$\begin{array}{l}\text { Case } \\
\text { NOM }\end{array}$} & \multicolumn{2}{|c|}{ Period I } & \multicolumn{2}{|c|}{ Period II } & \multicolumn{2}{|c|}{ Period III } \\
\hline & & 2 & $12.50 \%$ & 2 & $2.56 \%$ & o & $0.00 \%$ \\
\hline & $\mathrm{ACC}$ & 9 & $56.25 \%$ & 4 & $5.13 \%$ & $\mathrm{O}$ & $0.00 \%$ \\
\hline & DAT & $\mathrm{O}$ & $0.00 \%$ & $\mathrm{O}$ & $0.00 \%$ & $\mathrm{O}$ & $0.00 \%$ \\
\hline & GEN & $\mathrm{O}$ & $0.00 \%$ & 1 & $1.28 \%$ & 3 & $5.66 \%$ \\
\hline & $\mathrm{OBL}$ & 3 & $18.75 \%$ & 1 & $1.28 \%$ & $\mathrm{O}$ & $0.00 \%$ \\
\hline & No ending & 2 & $12.50 \%$ & 70 & $89 \cdot 74 \%$ & $5^{\circ}$ & $94.34 \%$ \\
\hline & Total & 16 & $100.00 \%$ & 78 & $100.00 \%$ & 53 & $100.00 \%$ \\
\hline \multirow[t]{7}{*}{ Swedish } & NOM & 8 & $33 \cdot 33 \%$ & 30 & $42.86 \%$ & 1 & $2.04 \%$ \\
\hline & ACC & 11 & $45.83 \%$ & 27 & $38.57 \%$ & 3 & $6.12 \%$ \\
\hline & DAT & 1 & $4.16 \%$ & 9 & $12.86 \%$ & o & $0.00 \%$ \\
\hline & GEN & 1 & $4.16 \%$ & 2 & $2.86 \%$ & o & $0.00 \%$ \\
\hline & OBL & 3 & $12.50 \%$ & 2 & $2.86 \%$ & o & $0.00 \%$ \\
\hline & No ending & $\mathrm{O}$ & $0.00 \%$ & $\mathrm{O}$ & $0.00 \%$ & 45 & $91.84 \%$ \\
\hline & Total & 24 & $100.00 \%$ & 70 & $100.00 \%$ & 49 & $100.00 \%$ \\
\hline \multirow[t]{7}{*}{ Icelandic } & NOM & 9 & $64.29 \%$ & 6 & $28.57 \%$ & 4 & $57.14 \%$ \\
\hline & ACC & $\mathrm{O}$ & $0.00 \%$ & 13 & $61.90 \%$ & 1 & $14.29 \%$ \\
\hline & DAT & 5 & $35 \cdot 71 \%$ & 2 & $9 \cdot 52 \%$ & 2 & $28.57 \%$ \\
\hline & GEN & $\mathrm{O}$ & $0.00 \%$ & o & $0.00 \%$ & o & $0.00 \%$ \\
\hline & OBL & $\mathrm{o}$ & $0.00 \%$ & o & $0.00 \%$ & o & $0.00 \%$ \\
\hline & No ending & $\mathrm{o}$ & $0.00 \%$ & o & $0.00 \%$ & $\mathrm{O}$ & $0.00 \%$ \\
\hline & Total & 14 & $100.00 \%$ & 21 & $100.00 \%$ & 7 & $100.00 \%$ \\
\hline
\end{tabular}

ited to sentence-initial subjects (see Skrzypek 2012, 2013). A classic example is quoted in (126).

(126) En diäkne war j enom stadh som heet montepessolanus EN deacon was in EN city which was.called Montepessolanus 'There was a deacon in a city called Montepessolanus.' (SV_Jart, Period II)

This presentative construction, familiar from the Icelandic sagas among others, is not found in Modern Swedish, where indefinite subjects are instead placed further from the beginning of the sentence. The tendency to place certain other elements, typically adverbials, in the initial position when the subject is indefinite begins in Old Swedish in Period II; see (127). 
(127) I Room war een keysare han hafdhe en-a dyghdhelik-a oc In Rome was EN emperor he had EN-ACC virtuous-ACC and gudhlik-a keysarinn-o godly-ACC empress-ACC 'There was an emperor in Rome who had a virtuous and godly wife.' (SV_ST, Period II)

There are also relatively high values for EN with the dative case, especially in Icelandic. At first, we considered the possibility of some correlation with animacy; however, the frequent uses of the dative turned out to be mainly locative phrases, as in (128).

(128) Sá eg pá bræður, Helga og Gunnar, í hell-i ein-um Saw I them brothers, Helgi and Gunnar, in cave-DAT en-DAT norður með á-nni.

north with river-DEF.DAT

'I saw these brothers, Helgi and Gunnar, in a cave north downstream.' (IS_Gun, Period II)

It seems that the high values for the dative case in Icelandic are the result of its use in prepositional phrases rather than any connection with the animacy of the referent.

\subsection{Definiteness, Subjecthood and Objecthood}

Having examined the interactions between definiteness and case we now turn to syntactic roles, primarily those of subject and object. We have decided to treat them separately from case, even if we expect the results for NOM and subject, and for ACC and object, to be largely similar. In the timeframe of our study oblique subjects can occasionally be found in both Danish and Swedish (with the decline of the case system, they gradually disappear) and in Icelandic (where they are preserved until modern times).

(129) Sýnist dróttning-u nú sem er, at peir gerðust nú seemed queen-DEF.DAT now which is, that they made.REFL now mann-venligir

man-attractive

'The queen found them attractive.' (IS_Ge, Period I) 
TABLE 43 The main syntactic functions of NPs in the corpus

\begin{tabular}{llllllll}
\hline N & $\begin{array}{l}\text { Syntactic } \\
\text { roles }\end{array}$ & \multicolumn{2}{c}{ Period I } & \multicolumn{2}{c}{ Period II } & Period III \\
& & & & & & & \\
\hline \multirow{2}{*}{ Danish } & subject & $246 / 1,097$ & $22.42 \%$ & $209 / 1,016$ & $20.57 \%$ & $156 / 787$ & $19.82 \%$ \\
& object & $305 / 1,097$ & $27.80 \%$ & $326 / 1,016$ & $32.09 \%$ & $214 / 787$ & $27.19 \%$ \\
\multirow{2}{*}{ Swedish } & subject & $297 / 1,194$ & $24.87 \%$ & $255 / 1,093$ & $23.33 \%$ & $103 / 635$ & $16.22 \%$ \\
& object & $363 / 1,194$ & $30.40 \%$ & $285 / 1,093$ & $26.08 \%$ & $190 / 635$ & $29.92 \%$ \\
Icelandic & subject & $354 / 1,536$ & $23.04 \%$ & $226 / 1,037$ & $21.79 \%$ & $157 / 648$ & $24.23 \%$ \\
& object & $418 / 1,536$ & $27.21 \%$ & $279 / 1,037$ & $26.90 \%$ & $182 / 648$ & $28.09 \%$
\end{tabular}

(130) en pó grunaði kóng hvað konu hún mundi vera and yet suspected king.Acc what woman she may be 'And yet the king suspected what kind of a woman she may be.' (IS_Vil, Period III)

We found 22 oblique subjects in our material (in all languages, but they are solely restricted to Period I), and thus conclude that subjects are overwhelmingly nominative, while objects may appear as accusative, dative or genitive phrases. See also Maling (2002) and Skrzypek (2005) for overviews of object marking in Old Icelandic and Old Swedish respectively.

As presented in Table 43, the proportions remain relatively stable in all three periods in Danish and Icelandic, while the Swedish results reveal more fluctuation in terms of the percentage of subjects, with somewhat lower results in Period III. This variation seems to be the result of a higher percentage of pronominal subjects in the Swedish texts from this period, compared with texts both in other languages and from other periods.

\subsubsection{Syntactic Functions and Definiteness}

Syntactic roles and definiteness exhibit a number of interdependencies, and languages seem to pattern differently with respect to how subject or object role may affect definite marking or its absence. The best recognized interdependencies are differential case marking in objects and definite object marking (for an overview and typology see Lyons C. 1999:200-205). In languages exhibiting such interdependencies we find that objects differ in case marking depending on whether or not they are definite.

It has further been noted that subjects may remain unmarked for definiteness, even if they are definite, as long as they are located clause-initially, as this 
position creates a so-called definiteness effect. As subjects tend to be topics (a cross-linguistic tendency; Lyons C. 1999:230), this interaction between syntactic role and definiteness marking seems to be secondary.

North Germanic does not demonstrate differential case marking, but it has been claimed that at the onset of definite article grammaticalization only objects that were definite and not clause-initial (and therefore not subject to a definiteness effect) were marked for definiteness. All elements that could be considered definite due to their position in the clause remained unmarked. Such a view is advocated in Leiss (2000, 2007) and in Abraham (2007). In her discussion of the Old Icelandic data, Leiss quotes an example of possible underspecification of the object in one of the most famous excerpts from Heimskringla (ca. 1225), quoted here as (131).

(131) pá verpr hann varr vip gripung-enn ok reið til ok then became he aware of ox-DEF and rode to and vill drepa hann gripungr snýr ímóti ok kom konungr wants kill him ox turns towards and came king lagi á hann ok skar ór spjót-it gripungr stakk stab on him and cut out lance-DEF ox stuck horn-onom i sípo hest-inum svá at hann fell horn-DEF.DAT.PL in side horse-DEF.DAT so that he fell pegar flatr ok svá konungr pá hljóp konungr á føtr immediately flat and so king then jumped king on feet ok vill bregða sverði griðungr stakk pá horn-unum and wants draw sword ox stuck then horn-DEF.DAT.PL fyrir brjóst honum svá at á kafi stóð pá komu at for breast him so that on depth stood then came to konung-s menn drópu gripung-enn.

king-GEN men killed ox-DEF

'He observed at last that it was the bull, and rode up to it to kill it. The bull turned round suddenly, and the king struck him with his spear; but it tore itself out of the wound. The bull now struck his horn in the side of the horse, so that he instantly fell flat on the earth with the king. The king sprang up, and was drawing his sword, when the bull struck his horns right into the king's breast. The king's men then came up and killed the bull.' (Heimskringla, cf. Nygaard 1905:47, Møller 1945:36, Heusler 1950:125, Leiss 2000:38-39; translation by Samuel Laing, London 1844) 
Admittedly, the example exhibits exactly the predicted distribution: definite marking appears only with the object and not with the subject, despite the latter being anaphoric. However, Leiss does not provide any more examples or indeed statistical data to support this hypothesis. In our Icelandic corpus we found only 16 instances of NPs that are objects, are direct anaphors (thus identifiable) and appear as BNs. Nine of these involve the noun konung 'king', three biskop 'bishop' and one abot 'prior'. The reason for their bare form may have nothing to do with their syntactic function, since they represent Hawkins' 'larger situation use', and in a limited context, of one country or one parish, are unique. We find a number of anomalies and inconsistencies similar to those reported in Leiss (2000), where the referent is presented as a BN when it is a subject, but as a definite if it is an object, as in (132).

\section{(132) Um kveld-it, er konungr kom heim ok haffi setzt i} In evening-DEF, as king came home and had sat in hásceti sitt, pá gengr dróttning fyrir konung-inn ok leiðir throne his, then went queen before king-DEF and lead svein-ana með sér ok segir konung-i allt, sem við nemr boy-DEF.PL wih her and says king-DAT all, which before named ok hverju hon hafði keypt við ambátt-ina ok biðr and which she had bought from servant.woman-DEF and asks konung hrinda af sér reiði. king dismiss of self anger 'In the evening, when the king had come home and sat in his throne, the queen came before him leading the boys and told the king all that was told here before about how she had bought the boys from the servant-woman and she asked the king to hold his anger.' (IS_Ge, Period I)

In example (133) there does not seem to exist a clear connection between either syntactic function or case and definiteness marking or the lack thereof.

(133) En tima per iohannes prcedicape fik han se en ungan suen en time there Johannes preached got he see EN young boy venan ok po vildan iohannes fik biskop-e suen-en ii beautiful and though wild Johannes got bishop-DAT boy-DEF in hand [...] Iohannes kom atar tel stap-en ok sporpe at hand Johannes came back to town-DEF and asked about suen-en-om biscop-en sagpe hanom vm suen-en som boy-DEF-DAT bishop-DEF said him about boy-DEF which 
sant var Johannes gaf biskop skuld for vangømo

true was Johannes gave bishop.DAT guilt for negligence

'One time as Johannes was preaching, he saw a young boy, beautiful but wild. Johannes gave a/the bishop charge of the boy. [...] Johannes returned to the town and asked about the boy. The bishop told him the truth. Johannes blamed the bishop for negligence.' (SV_Bur, Period I)

Leiss' idea of a definite article appearing first in NPs used as clause-internal objects (since this syntactic context does not create a definiteness effect) but later with subjects (as this context does create a definiteness effect rendering the article superfluous) does not find support in the data, as presented in Figures 8-10. The definite is used to mark subjects in Period I, and this seems to be its main domain, particularly in Danish texts, in which there are more definite subjects than there are definite objects in all three periods. In Swedish the proportions are more equal in Period I and Period III, but there are almost thrice as many definite subjects than there are definite objects in Period II. Icelandic exhibits quite diverse results: in Period I there are more definite subjects than objects, but that proportion is reversed in Period III.

In Table 44, we compare the overall number of subjects in the corpus with the number of definite subjects. The proportion is arrived at through proportional statistics with the query: out of all of the nouns marked as -IN, how many are subjects?

In both Danish and Swedish, defNPs appear in the role of subject more frequently than NPs do generally. It seems that the incipient definite article favours the role of subject. No comparable discrepancies were found in Icelandic; even if the proportions for all NPs and defNPs are not identical, they are quite similar and consistent throughout all three periods.

It should be noted that definite marking (-IN) is used despite the fact that the context is considered to be definite already (by virtue of the topicality of the subject and the overwhelmingly most frequent initial position of the subject). So -IN, even at the onset of grammaticalization, is not reserved for unclear cases (typically objects), but rather develops first in contexts that are prototypically definite. Therefore, we may talk of morphologization of the category of definiteness, i.e., acquisition of a morphological exponent.

In Table 45 we compare the overall number of subjects in the corpus with the number of subjects marked with the indefinite article (EN).

The surprisingly high percentage of indefinite subjects in Icelandic in Period I and III is an illustration of the fact that EN could be used as a presentative marker in Icelandic, although without progressing further on the grammaticalization scale. Its use was reserved for introducing salient discourse referents. 


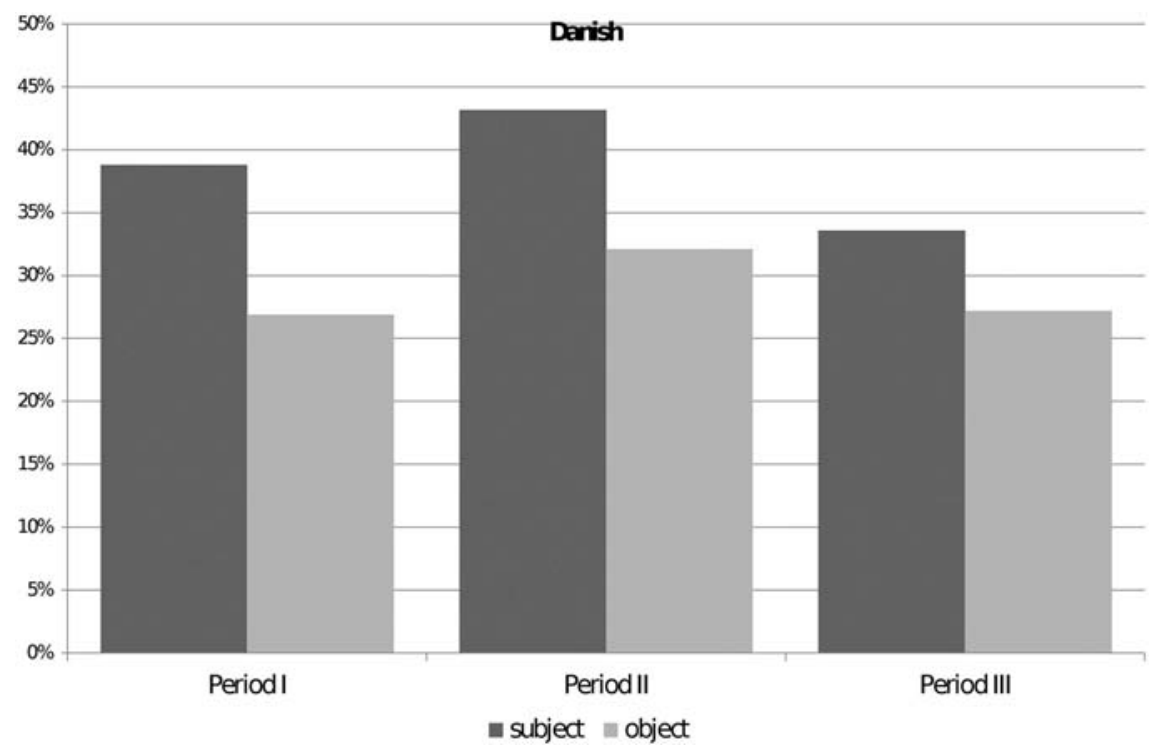

FIGURE 8 Proportions of definite subjects and objects in Danish

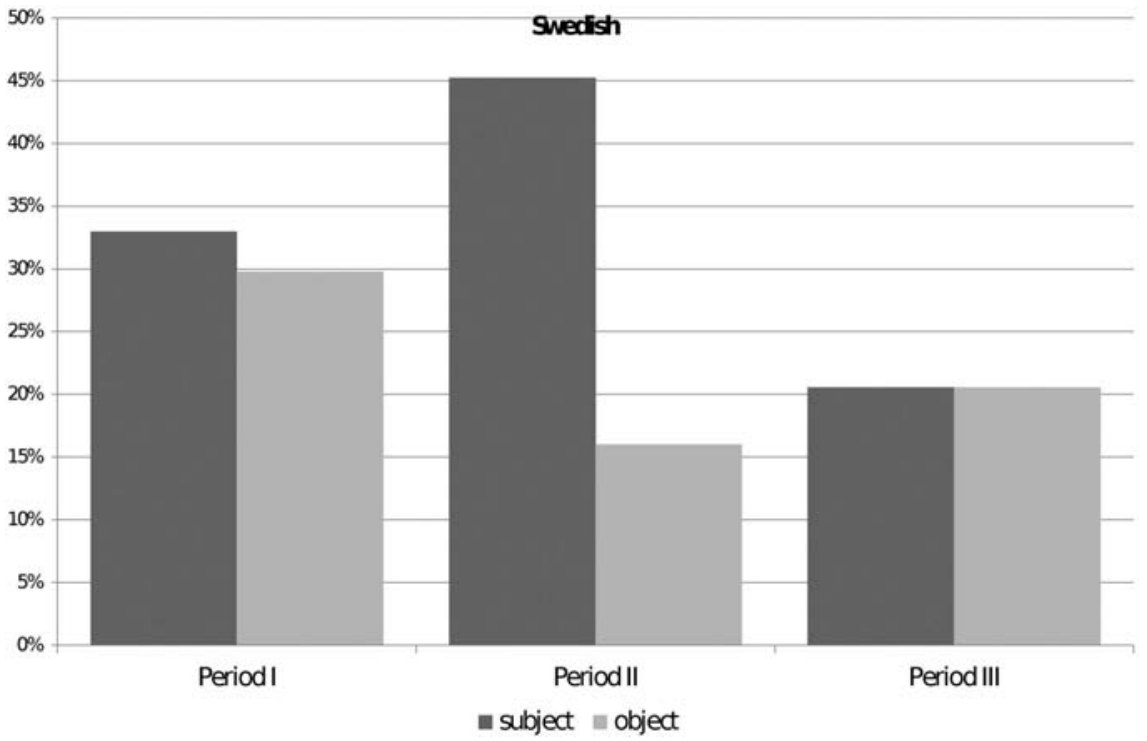

FIGURE 9 Proportions of definite subjects and objects in Swedish 


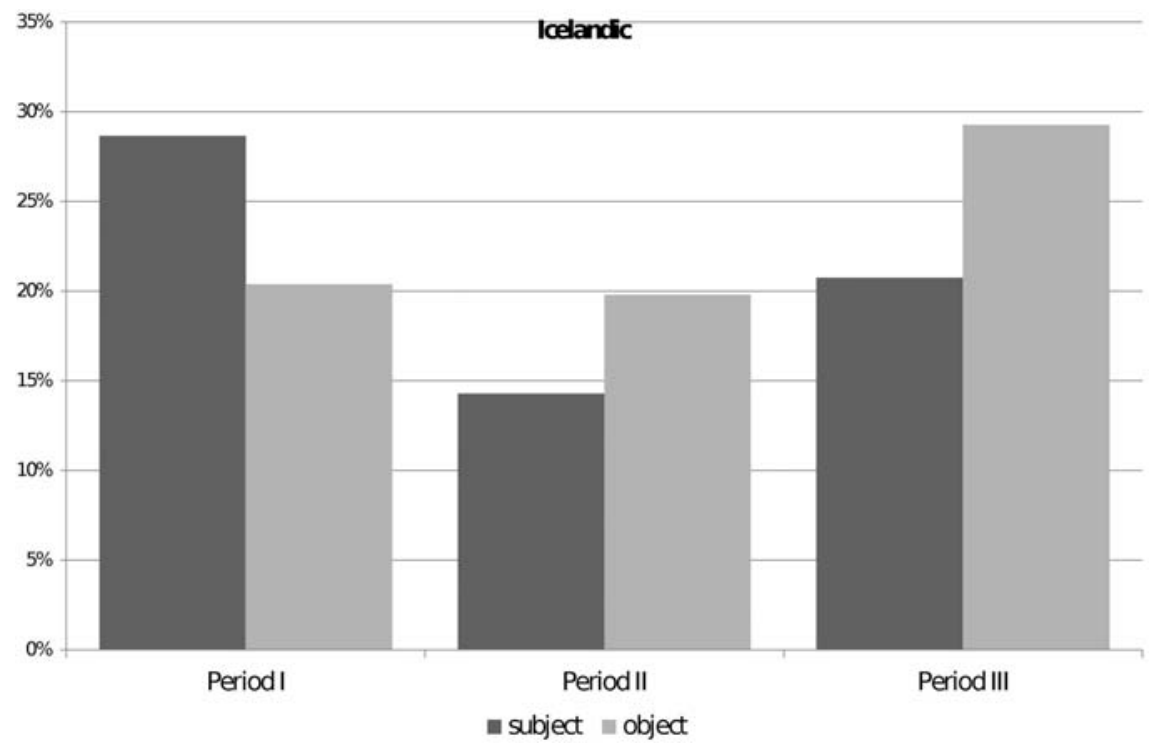

FIGURE 10 Proportions of definite subjects and objects in Icelandic

TABLE 44 Definite subjects in the corpus

\begin{tabular}{llllllll} 
Subject & Context & \multicolumn{2}{c}{ Period I } & \multicolumn{2}{c}{ Period II } & \multicolumn{2}{c}{ Period III } \\
\hline \multirow{2}{*}{ Danish } & SBJ / N & $246 / 1,097$ & $22.42 \%$ & $209 / 1,016$ & $20.57 \%$ & $156 / 787$ & $19.82 \%$ \\
& SBJ / -IN & $26 / 67$ & $38.81 \%$ & $60 / 139$ & $43.17 \%$ & $48 / 143$ & $33.57 \%$ \\
\multirow{3}{*}{ Swedish } & SBJ / N & $297 / 1,194$ & $24.87 \%$ & $255 / 1,093$ & $23.33 \%$ & $103 / 635$ & $16.22 \%$ \\
& SBJ / -IN & $31 / 94$ & $32.98 \%$ & $134 / 294$ & $45.58 \%$ & $22 / 107$ & $20.56 \%$ \\
Icelandic & SBJ / N & $354 / 1,536$ & $23.04 \%$ & $226 / 1,037$ & $21.79 \%$ & $157 / 648$ & $24.23 \%$ \\
& SBJ / -IN & $45 / 157$ & $28.66 \%$ & $13 / 91$ & $14.29 \%$ & $16 / 82$ & $19.51 \%$
\end{tabular}

TABLE 45 Indefinite subjects in the corpus

\begin{tabular}{llllllll}
\hline Subject & \multirow{2}{*}{ Context } & \multicolumn{2}{c}{ Period I } & \multicolumn{2}{c}{ Period II } & \multicolumn{2}{c}{ Period III } \\
\hline \multirow{2}{*}{ Danish } & SBJ / N & $246 / 1,097$ & $22.42 \%$ & $209 / 1,016$ & $20.57 \%$ & $156 / 787$ & $19.82 \%$ \\
& SBJ / EN & $3 / 16$ & $18.75 \%$ & $15 / 78$ & $19.23 \%$ & $12 / 53$ & $22.64 \%$ \\
Swedish & SBJ / N & $297 / 1,194$ & $24.87 \%$ & $255 / 1,093$ & $23.33 \%$ & $103 / 635$ & $16.22 \%$ \\
& SBJ / EN & $19 / 24$ & $41.67 \%$ & $25 / 70$ & $35.71 \%$ & $9 / 49$ & $18.37 \%$ \\
Icelandic & SBJ / N & $354 / 1,536$ & $23.04 \%$ & $226 / 1,037$ & $21.79 \%$ & $157 / 648$ & $24.23 \%$ \\
& SBJ / EN & $7 / 14$ & $50.00 \%$ & $3 / 21$ & $14.29 \%$ & $5 / 7$ & $57.14 \%$ \\
& & & & & & & \\
\end{tabular}


TABLE 46 Definite objects in the corpus

\begin{tabular}{llllllll}
\hline Object & Context & \multicolumn{2}{c}{ Period I } & \multicolumn{2}{c}{ Period II } & \multicolumn{2}{c}{ Period III } \\
\hline \multirow{2}{*}{ Danish } & OBJ / N & $305 / 1,097$ & $27.80 \%$ & $326 / 1,016$ & $32.09 \%$ & $214 / 787$ & $27.19 \%$ \\
& OBJ / -IN & $18 / 67$ & $26.87 \%$ & $33 / 139$ & $23.74 \%$ & $22 / 143$ & $15.38 \%$ \\
\multirow{3}{*}{ Swedish } & OBJ / N & $363 / 1,194$ & $30.40 \%$ & $285 / 1,093$ & $26.08 \%$ & $190 / 635$ & $29.92 \%$ \\
& OBJ / -IN & $28 / 94$ & $29.79 \%$ & $49 / 294$ & $16.66 \%$ & $22 / 107$ & $20.56 \%$ \\
Icelandic & OBJ / N & $418 / 1,536$ & $27.21 \%$ & $279 / 1,037$ & $26.90 \%$ & $182 / 648$ & $28.09 \%$ \\
& OBJ / -IN & $32 / 157$ & $20.38 \%$ & $18 / 91$ & $19.78 \%$ & $24 / 82$ & $29.27 \%$ \\
& & & & & & & \\
\hline
\end{tabular}

(134) Kona ein fór of morgun snemma að kanna fjöru pví að woman EN went of morning early to search shore for that búandi hennar var eigi heima. Sér hún sỉan örkn mikið liggja husband her was not home sees she then seal large lie á steini skammt frá sér. on stone close from her. 'There was a woman who went out early one morning in search of her husband who was not at home. She saw a large seal lying on a stone not far from her.' (IS_Jart, Period I)

The story, the introduction of which is given in (134), continues with a description of the woman's actions and her slaying of the seal. It may be noted that the woman is consistently referred to pronominally (she, her, hers, etc.) and the seal appears in the definite form of selr 'seal', a part of its full name, örknselr (örkn is most likely related to Latin orca). We may further note that EN could be either pre- or postposed (see also section 5.6 on the rise of the indefinite article in Icelandic for more discussion on the position of the indefinite article).

As we noted in Table 44, the definite seems to favour subjects at the onset of grammaticalization. The results presented in Table 46 regarding the object role are inconclusive. In many cases the definite neither favours nor disfavours the role of object, since the values for all NPs and for defNPs are similar, especially for Danish and Swedish in Period I and Icelandic in Period III. Otherwise, definite objects are considerably under-represented in comparison with the overall proportion of objects in the corpus.

In modern North Germanic new discourse referents are mainly introduced as objects (unless some presentative structures are used to introduce them as subjects). We would therefore expect the percentage of indefNPs among 
TABLE 47 Indefinite objects in the corpus

\begin{tabular}{llllllll}
\hline \multirow{2}{*}{ Object } & Context & \multicolumn{2}{c}{ Period I } & \multicolumn{2}{c}{ Period II } & \multicolumn{2}{c}{ Period III } \\
\hline \multirow{2}{*}{ Danish } & OBJ / N & $305 / 1,097$ & $27.80 \%$ & $326 / 1,016$ & $32.09 \%$ & $214 / 787$ & $27.19 \%$ \\
& OBJ / EN & $5 / 16$ & $31.25 \%$ & $40 / 78$ & $51.28 \%$ & $13 / 53$ & $24.53 \%$ \\
Swedish & OBJ / N & $363 / 1,194$ & $30.40 \%$ & $285 / 1,093$ & $26.08 \%$ & $190 / 635$ & $29.92 \%$ \\
& OBJ / EN & $7 / 24$ & $29.17 \%$ & $18 / 70$ & $25.71 \%$ & $19 / 49$ & $38.78 \%$ \\
Icelandic & OBJ / N & $418 / 1,536$ & $27.21 \%$ & $279 / 1,037$ & $26.90 \%$ & $182 / 648$ & $28.09 \%$ \\
& OBJ / EN & O/ $/ 14$ & $0.00 \%$ & $6 / 21$ & $28.57 \%$ & $1 / 7$ & $14.29 \%$ \\
& & & & & & & \\
\hline
\end{tabular}

objects to be higher than among the total number of NPs. This prediction is borne out to some extent (see Table 47) and there is a clear preference for indefNPs as objects in Danish in Period II and Swedish in Period III. Again, these results suggest that the developments in Danish precede those in Swedish, with the grammaticalization of the indefinite article already being more advanced in Danish than in Swedish in Period II.

Interestingly, no indefinite objects marked with EN were found in Icelandic in Period I, although they appear in later texts, as in (135).

(135) Og að enduðum gjöfum lét jarl fram bera eina hörpu. And to final gifts let jarl forth bring EN harp 'And for the final gift the jarl let bring forth a harp.' (IS_Vig, Period II)

The results presented above indicate quite clearly that the incipient definite article is more likely to appear with subjects. The indefinite article favours subjects in Swedish, too, but no such preference was found in either Danish or Icelandic. With objects, there is a more pronounced preference for indefNPs than for defNPs. Article usage seems to have followed the given-new dichotomy associated with subject and object roles rather than being connected with the syntactic roles as such.

\subsection{Definiteness and Animacy}

Let us now consider the interactions between the animacy of an NP and definiteness. Animacy has been shown to play a significant role in the placing and marking of NPs (Dahl and Fraurud 1996, Yamamoto 1999). Animacy is also connected to the notion of topicality and saliency of information, which is also 
TABLE 48 Animate and inanimate NPs in the corpus

\begin{tabular}{llrrrrrr}
\hline N & Animacy & \multicolumn{2}{c}{ Period I } & \multicolumn{2}{c}{ Period II } & \multicolumn{2}{c}{ Period III } \\
\hline \multirow{2}{*}{ Danish } & animate & 463 & $42.21 \%$ & 464 & $45.67 \%$ & 330 & $41.93 \%$ \\
& inanimate & 634 & $57.79 \%$ & 552 & $54.33 \%$ & 457 & $58.07 \%$ \\
& Total & 1,097 & $100.00 \%$ & 1,016 & $100.00 \%$ & 787 & $100.00 \%$ \\
\multirow{5}{*}{ Swedish } & animate & 567 & $47.49 \%$ & 421 & $38.52 \%$ & 188 & $29.61 \%$ \\
& inanimate & 627 & $52.51 \%$ & 672 & $61.48 \%$ & 447 & $70.39 \%$ \\
& Total & 1,194 & $100.00 \%$ & 1,093 & $100.00 \%$ & 635 & $100.00 \%$ \\
& animate & 601 & $39.13 \%$ & 394 & $37.99 \%$ & 267 & $41.20 \%$ \\
& inanimate & 935 & $60.87 \%$ & 643 & $62.01 \%$ & 381 & $58.80 \%$ \\
& Total & 1,536 & $100.00 \%$ & 1,037 & $100.00 \%$ & 648 & $100.00 \%$ \\
& & & & & & & \\
\hline
\end{tabular}

strongly linked to definiteness. Language is anthropocentric in nature, which results in the centralization and singling out of animate and human referents as the most salient.

As with singulars and plurals, we would expect the relative frequencies of animates and inanimates to remain constant for each language, although more variation may be expected than in the case of number, since the character of the text (e.g., the presence of many human referents) may skew the results.

The overall results for all nouns in the corpus (Table 48) reveal that animate nouns constitute ca. $40 \%$ of all nouns, and the percentage is similar in all periods for Danish and Icelandic. Swedish exhibits more variation between the periods studied; however, on the whole, there are ca. 40\% of animates among all nouns in the Swedish corpus as well, with different distributions in each period.

In both Danish and Swedish, animate NPs predominate among the defNPs (see Table 49). The proportions change first in Period III. However, the dominance of animate NPs is not absolute, and inanimate definites constitute ca. $40 \%$ of all definites in Danish and Swedish as early as in Period I. Icelandic, on the other hand, exhibits a clear dominance of inanimate NPs among the definite NPs.

The data for indefinite NPs presented in Table $5^{\circ}$ indicate a dominance of inanimates in Period I in all three languages; in both Danish and Icelandic the values in Period III are similar to the overall results reported in Table 48. Surprisingly, while the Swedish results for Period I and Period III are very similar, there is a different picture in Period II. However, we believe that this is a conse- 
TABLE 49 Animate and inanimate definite NPs (-IN) in the corpus

\begin{tabular}{llrrrrrr}
\hline -IN & Animacy & \multicolumn{2}{c}{ Period I } & \multicolumn{2}{c}{ Period II } & \multicolumn{2}{l}{ Period III } \\
\hline \multirow{2}{*}{ Danish } & animate & 38 & $56.72 \%$ & 84 & $60.43 \%$ & 66 & $46.15 \%$ \\
& inanimate & 29 & $43.28 \%$ & 55 & $39.57 \%$ & 77 & $53.85 \%$ \\
& Total & 67 & $100.00 \%$ & 139 & $100.00 \%$ & 143 & $100.00 \%$ \\
\multirow{3}{*}{ Swedish } & animate & 61 & $64.89 \%$ & 168 & $57.14 \%$ & 36 & $33.64 \%$ \\
& inanimate & 33 & $35.11 \%$ & 126 & $42.86 \%$ & 71 & $66.36 \%$ \\
& Total & 94 & $100.00 \%$ & 294 & $100.00 \%$ & 107 & $100.00 \%$ \\
& animate & 57 & $36.31 \%$ & 23 & $25.27 \%$ & 15 & $18.52 \%$ \\
& inanimate & 100 & $63.69 \%$ & 68 & $74.73 \%$ & 66 & $81.48 \%$ \\
& Total & 157 & $100.00 \%$ & 91 & $100.00 \%$ & 82 & $100.00 \%$ \\
\hline
\end{tabular}

TABLE 50 Animate and inanimate indefinite NPs (EN) in the corpus

\begin{tabular}{llrrrrrr}
\hline EN & Animacy & \multicolumn{2}{c}{ Period I } & \multicolumn{2}{l}{ Period II } & \multicolumn{2}{l}{ Period III } \\
\hline \multirow{2}{*}{ Danish } & animate & 3 & $18.75 \%$ & 32 & $41.03 \%$ & 29 & $54.72 \%$ \\
& inanimate & 13 & $81.25 \%$ & 46 & $58.97 \%$ & 24 & $45.28 \%$ \\
& Total & 16 & $100.00 \%$ & 78 & $100.00 \%$ & 53 & $100.00 \%$ \\
\multirow{3}{*}{ Swedish } & animate & 8 & $33.33 \%$ & 37 & $52.86 \%$ & 16 & $32.65 \%$ \\
& inanimate & 16 & $66.67 \%$ & 33 & $47.14 \%$ & 33 & $67.35 \%$ \\
\multirow{3}{*}{ Icelandic } & Total & 24 & $100.00 \%$ & 70 & $100.00 \%$ & 49 & $100.00 \%$ \\
& animate & 3 & $21.43 \%$ & 5 & $23.81 \%$ & 4 & $57.14 \%$ \\
& inanimate & 11 & $78.57 \%$ & 16 & $76.19 \%$ & 3 & $42.86 \%$ \\
& Total & 14 & $100.00 \%$ & 21 & $100.00 \%$ & 7 & $100.00 \%$
\end{tabular}

quence of the fact that the majority of the texts included in the material from Period II are shorter (in particular Jart and HML, which are collections of short morality tales) than the texts in other periods. Therefore, there are more characters to be introduced, and this is done by means of EN. The preference for animate referents is also a result of the fact that these morality tales always feature humans as the main characters.

The percentage of animates among definite NPs (-IN) is higher than the corresponding percentage of animates among all NPs in the corpus, as presented in Table 51. While the latter is consistently around $40 \%$ in all languages and in all periods, we note some variation within the defNPs in both Danish and 
TABLE 51 Animate NPs in definite form — a comparison with all nouns

\begin{tabular}{llllllll} 
Animate NPs & Context & \multicolumn{2}{c}{ Period I } & \multicolumn{2}{c}{ Period II } & \multicolumn{2}{c}{ Period III } \\
\hline \multirow{2}{*}{ Danish } & ANIM / N & $463 / 1,097$ & $42.21 \%$ & $464 / 1,016$ & $45.67 \%$ & $330 / 787$ & $41.93 \%$ \\
& ANIM / -IN & $38 / 67$ & $56.72 \%$ & $84 / 139$ & $60.43 \%$ & $66 / 143$ & $46.15 \%$ \\
Swedish & ANIM / N & $567 / 1,194$ & $47.49 \%$ & $421 / 1,093$ & $38.52 \%$ & $188 / 635$ & $29.61 \%$ \\
& ANIM / -IN & $61 / 94$ & $64.89 \%$ & $168 / 294$ & $57.14 \%$ & $36 / 107$ & $33.64 \%$ \\
Icelandic & ANIM / N & $601 / 1,536$ & $39.13 \%$ & $394 / 1,037$ & $37.99 \%$ & $267 / 648$ & $41.20 \%$ \\
& ANIM / -IN & $57 / 157$ & $36.31 \%$ & $23 / 91$ & $25.27 \%$ & $15 / 82$ & $18.52 \%$ \\
& & & & & & &
\end{tabular}

TABLE 52 Animate NPs in indefinite form - a comparison with all nouns

\begin{tabular}{|c|c|c|c|c|c|c|c|}
\hline \multirow{2}{*}{$\begin{array}{l}\text { Animate NPs } \\
\text { Danish }\end{array}$} & \multirow{2}{*}{$\begin{array}{l}\text { Context } \\
\text { ANIM / N }\end{array}$} & \multicolumn{2}{|c|}{ Period I } & \multicolumn{2}{|c|}{ Period II } & \multicolumn{2}{|c|}{ Period III } \\
\hline & & $463 / 1,097$ & $42.21 \%$ & $464 / 1,016$ & $45.67 \%$ & $330 / 787$ & $41.93 \%$ \\
\hline & ANIM / EN & $3 / 16$ & $18.75 \%$ & $32 / 78$ & $41.03 \%$ & $29 / 53$ & $54.72 \%$ \\
\hline \multirow[t]{2}{*}{ Swedish } & ANIM / N & $567 / 1,194$ & $47.49 \%$ & $421 / 1,093$ & $38.5^{2} \%$ & $188 / 635$ & $29.61 \%$ \\
\hline & ANIM / EN & $8 / 24$ & $33 \cdot 33 \%$ & $37 / 70$ & $5^{2.86 \%}$ & $16 / 49$ & $32.65 \%$ \\
\hline \multirow[t]{2}{*}{ Icelandic } & ANIM / N & $601 / 1,536$ & $39.13 \%$ & $394 / 1,037$ & $37.99 \%$ & $267 / 648$ & $41.20 \%$ \\
\hline & ANIM / EN & $3 / 14$ & $21.43 \%$ & $5 / 21$ & $23.81 \%$ & $4 / 7$ & $57.14 \%$ \\
\hline
\end{tabular}

Swedish. In Icelandic the proportions seem to be very similar for all NPs and defNPs in Period I, but in both Period II and III fewer defNPs are animate, while the percentage of animates among all NPs remains at the same level. An explanation of this may be the genre and type of the texts, as well as the kind of discourse referents which appear in them.

Comparing the proportions of animates in indefinite NPs and in all NPs in the corpus (Table $5^{2}$ ), we observe that the results are quite varied. Indefinite animate NPs are strongly under-represented in Period I in all languages, but this changes in Period II, when in Danish the results are very similar, and in Swedish animate indefinite NPs are over-represented (as mentioned above, the reason for this is most likely the text type). In Period III the percentage of animate indefinite NPs is considerably higher, in all of the languages, than the corresponding percentage for all NPs.

We have already considered (in section 4.3) the animacy hierarchy (Silverstein 1976, Comrie 1981) with respect to number marking, which is often lacking with abstract inanimates in North Germanic. The hierarchy is often cited in 
discussions of different patterns of morphological marking of grammatical categories, perhaps none more so than definiteness. C. Lyons (1999) is particularly critical of the explanatory power of such a hierarchy; he considers it rather an expression of 'some real cross-language generalizations' (Lyons C. 1999:215) which reflects a variation in salience, or prominence, between different types of referents, where human referents would intuitively be the most salient ones (ibid.).

The animacy hierarchy is motivated functionally, as for example most subjects tend to be more animate and definite than objects. C. Lyons points out that this leads to compensating morphological marking if the situation deviates from the stereotypical one and the object is more animate and definite than the subject (Lyons C. 1999:214). This insight is also the foundation of Leiss' idea that definite marking originated in the object position, to mark objects that were definite, before such marking appeared on subjects, which were definite by virtue of their initial position in the clause (Leiss 2000, 2007). As already noted in section 4.6, this hypothesis is not borne out in the material of this study, which clearly demonstrates a preference for animate subjects (in the nominative) to be marked as definite before objects.

\subsection{Definiteness and Type of Reference}

So far, we have considered the interactions between definiteness and other grammatical phenomena. In the remaining part of the chapter, we address a different interdependency, namely that between definiteness and type of reference.

In Chapter 2 we discussed the meaning of definiteness and the uses of the definite article, noting that they are not isomorphic, but that article languages can use articles to different extents, depending on the context. We discussed a typology of definite article uses as presented by Hawkins (1978) and noted some overlaps between certain uses and certain articles, in languages with more than one definite article (see also Schwarz F. 2009). All of these observations were synchronic; however, they are even more relevant diachronically. North Germanic originally had no definite (or indefinite) article, while modern North Germanic languages do. In the course of article grammaticalization we expect different article uses to be available for the incipient definite article, but not all simultaneously. We therefore turn to an analysis of the occurrence of -IN in each of the three uses: direct anaphora, indirect anaphora and larger situation use. As we did with grammatical categories above, we take each use of the definite article separately and discuss its representation in the corpus. 
TABLE 53 Expressions of direct anaphora in the corpus

\begin{tabular}{|c|c|c|c|c|c|c|c|}
\hline \multirow{2}{*}{$\begin{array}{l}\text { Direct } \\
\text { anaphora }\end{array}$} & \multirow{2}{*}{$\begin{array}{l}\text { Forms } \\
\text { BN }\end{array}$} & \multicolumn{2}{|c|}{ Period I } & \multicolumn{2}{|c|}{ Period II } & \multicolumn{2}{|c|}{ Period III } \\
\hline & & $98 / 241$ & $40.66 \%$ & $44 / 251$ & $17.53 \%$ & $17 / 194$ & $8.76 \%$ \\
\hline & $-I N$ & $31 / 241$ & $12.86 \%$ & $87 / 25^{1}$ & $34.66 \%$ & $74 / 194$ & $38.14 \%$ \\
\hline & DEN & $19 / 241$ & $7.88 \%$ & $34 / 251$ & $13.55 \%$ & $25 / 194$ & $12.89 \%$ \\
\hline & DEM & $15 / 241$ & $6.22 \%$ & $3^{2} / 25^{1}$ & $12.75 \%$ & $25 / 194$ & $12.89 \%$ \\
\hline \multirow[t]{4}{*}{ Swedish } & $\mathrm{BN}$ & $88 / 263$ & $33.46 \%$ & o / 305 & $0.00 \%$ & $1 / 124$ & $0.81 \%$ \\
\hline & $-\mathrm{IN}$ & $5^{2 / 263}$ & $19.77 \%$ & $218 / 305$ & $71.48 \%$ & $57 / 124$ & $45.97 \%$ \\
\hline & DEN & $10 / 263$ & $3.80 \%$ & $33 / 305$ & $10.82 \%$ & $24 / 124$ & $19.36 \%$ \\
\hline & DEM & $18 / 263$ & $6.84 \%$ & $23 / 305$ & $7 \cdot 54 \%$ & $27 / 124$ & $21.77 \%$ \\
\hline \multirow[t]{4}{*}{ Icelandic } & $\mathrm{BN}$ & $81 / 314$ & $25.80 \%$ & $5^{1 / 177}$ & $28.81 \%$ & $46 / 127$ & $36.22 \%$ \\
\hline & $-\mathrm{IN}$ & $86 / 314$ & $27 \cdot 39 \%$ & $42 / 177$ & $23.73 \%$ & $47 / 127$ & $37.01 \%$ \\
\hline & DEN & $41 / 314$ & $13.06 \%$ & $9 / 177$ & $5.08 \%$ & $5 / 127$ & $3.94 \%$ \\
\hline & DEM & $44 / 314$ & $14.01 \%$ & $45 / 177$ & $25.42 \%$ & $9 / 127$ & $7.09 \%$ \\
\hline
\end{tabular}

We follow the proposed grammaticalization chain (see Chapter 2), beginning with direct anaphora.

The expressions considered here include bare nouns (BN), the incipient definite article annotated with -IN, and two types of other determiners: the annotation DEN refers to the proximal demonstrative sá 'this', while DEM refers to other determiners, such as thenne 'that'.

The results presented in Table 53 reveal a common tendency in Danish and Swedish to avoid BNs in direct anaphoric uses as the grammaticalization of the definite article progresses. In Period I we find BNs as direct anaphors in about one-third of all Swedish examples and over $40 \%$ of the Danish ones. As early as Period II they vanish in Swedish, while in Danish they constitute ca. $19 \%$ of all direct anaphors. The Icelandic results, on the other hand, exhibit some variation between Period I and III; surprisingly the percentage of BNs increases with time.

(136) Pess er getið eitt sinn að kóng-ur var á skóg farinn með it is told EN time that king-NOM was on forest gone with hirð sinni sem oftar

court his as often

'It is told that once the king was gone to the woods with his court, as he often did.' (IS_Vil, Period III) 
In (136), the discourse referent kóng-ur 'king-NOM' was introduced as Ríkharður kongur two lines earlier, so it is neither new nor unique. Notably, the direct anaphors in Icelandic that appear as BNs are almost exclusively NPs including the noun konungr 'king' (in Period I also drottning 'queen'). Even though it is always a specific referent, introduced early on in the story, the noun appears bare, as if it were used to refer uniquely.

The BNs used as direct anaphors in Danish and Swedish are less frequent and sometimes not necessarily anaphors at all. Consider the example in (137) from Swedish, Period III.

(137) thetta mäkta skipp-ed [...] steg thän dristog-a man-en oc this mighty ship-DEF rose DEF bold-wK man-DEF and strängh-e riddar-en Jason till skip-s $m z$ mangha ädel-a strong-WK knight-DEF Jason to ship-GEN with many noble-PL oc fri-burn-e män aff tessalia and free-born-PL men of Thessalia 'This mighty ship [...] the bold and strong knight Jason came onboard [= to the ship] with many noble and free-born men of Thessalia.' (SV_Did, Period III)

The expression till skips, although it may refer anaphorically to the previously mentioned ship in the phrase 'this mighty ship', may also be non-referential, a use of BNs similar to the modern pseudo-incorporation in Danish and Swedish (Asudeh and Mikkelsen 200o). In Periods II and III in Danish and Swedish the incipient definite article (-IN) is used in the majority of direct anaphors.

It is important to note that Swedish (and also Norwegian) developed socalled double definiteness in NPs in which the head noun is accompanied by an adjective; see example (138a). The proximal demonstrative sá 'this' grammaticalized in Swedish into a free preposed definite article, $\mathrm{den} / \mathrm{det} / \mathrm{de}$ 'the' (its form depending on the gender and number of the head noun). Double definiteness did not develop in Danish or Icelandic (with the exception of poetry and older texts, where the preposed hinn occasionally appears). In Danish only the preposed article DEN occurs in an NP with an adjective, blocking the suffixed article, while in Icelandic only the suffixed article occurs. In all languages the adjective appears in its weak form in definite NPs.

\section{Swedish}

(138) a. det stor-a hus-et

DEF big-WK house-DEF 
Danish

b. det stor-e hus

DEF big-wK house

Icelandic

c. stór-a hús-ið

big-WK house-DEF

'the big house'

It is thus possible, in our corpus, that both demonstratives DEN and DEM cooccur within the same NP with the suffixed definite article -IN (for DEN see examples (139-141) and (143), from DEM example (142)). In Old Swedish determiners co-occur with -IN relatively frequently in comparison with the other two languages, out of all NPs with the suffixed article -IN, 15.7\% co-occur with demonstratives, as in examples (139-143).

(139) pön sami att-in

DEF same family-DEF

'the same family' (SV_OgL, Period I)

(140) Vm ena nat war thän riddar-in $j$ enom stadh näst the on EN night was DEF knight-DEF.NOM in EN town next DEF quinn-onne som diäfwl-en war $j$ woman-DEF.ACC which devil-DEF was in 'One night the knight was in a town near the place where the possessed woman stayed.' (SV_Jart, Period II)

(141) Nu litin tima ther äpte tha doo thän sami riddarin. now little time there after then died DEF same knight-DEF ther nu sagdhi-s aff which now told-REFL of 'A short time afterwards the same knight of which we spoke here died.' (SV_Jart, Period II)

(142) Jak seer thz thässa vng-a gran-en haffwer swa mykith op I see that this young-WK spruce-DEF has so much up wäxt thz hon fortagher the stor-o at wäxa grown that she deprives DEF large-WK to grow 'I see that this young spruce has grown so much that it does not allow the large one to continue growing. (SV_SVM, Period II) 
(143) oc wndradho alle hwat gudh-i täkti-s framdelis göra and wondered all what god-DAT thought-REFL henceforth do $m z$ the klene iomffrw-n-ne with DEF delicate maiden-DEF-DAT 'And all wondered what God would do henceforth do with the delicate maiden.' (SV_Linc, Period III)

In Danish the co-occurrence is very rare; only $4 \%$ of NPs with -IN co-occur with demonstratives, as in examples (144-145). ${ }^{4}$ Interestingly, the only examples of this type of double definiteness are found within one Danish text, Sjalens trost, which might be heavily influenced by the Swedish text, as both were translated from the same German source text around the same time. This is consistent with the fact that, under the periods studied, double definiteness was developing in Swedish but not in Danish (see also section 2.4.1.1 on double definiteness).

(144) Tha com oc then ful-r mordhar-in løbande oc grep then came also DEF vile-ST murderer-DEF running and seized the cedhl-a quinn-ona $i$ har-it DEF noble-WK woman-DEF in hair-DEF 'Then the vile murderer came running and grabbed the noble woman by the hair.' (DA_ST, Period II)

(145) oc drikkir hon af the yrte-ne tha faar hon bot and drinks she of DEF herb-DEF then receives she cure 'And if she drinks the herb she will be cured.' (DA_ST, Period II)

In Icelandic there are even fewer examples of the co-occurrence: only $2.4 \%$ of all instances of -IN co-occur with demonstratives. The example (146) is the only one in the Icelandic corpus where the distal demonstrative sá co-occurs with the suffixed article.

(146) og hafi sá okkar hring-inn sem betur veitir and had that our ring-DEF.NOM which better knows 'And one which knows better will have this ring of ours.' (IS_Vil, Period III)

4 Note that in example (144) the adjective 'vile' appears in its strong form; compare to example $(275)$ in section 6.1from the same text in Swedish where the corresponding adjective is in a weak form. 
TABLE 54 Expressions of indirect anaphora in the corpus

\begin{tabular}{|c|c|c|c|c|c|c|c|}
\hline \multirow{2}{*}{$\begin{array}{l}\text { Indirect } \\
\text { anaphora }\end{array}$} & \multirow{2}{*}{$\begin{array}{l}\text { Forms } \\
\text { BN }\end{array}$} & \multicolumn{2}{|c|}{ Period I } & \multicolumn{2}{|c|}{ Period II } & \multicolumn{2}{|c|}{ Period III } \\
\hline & & $59 / 243$ & $24.28 \%$ & $13 / 230$ & $5.65 \%$ & $11 / 215$ & $5.12 \%$ \\
\hline & $-\mathrm{IN}$ & $19 / 243$ & $7.82 \%$ & $26 / 230$ & $11.30 \%$ & $44 / 215$ & $20.47 \%$ \\
\hline & DEN & $15 / 243$ & $6.17 \%$ & $13 / 230$ & $5.65 \%$ & $9 / 215$ & $4.19 \%$ \\
\hline & DEM & $6 / 243$ & $2.47 \%$ & $4 / 230$ & $1.74 \%$ & $3 / 215$ & $1.40 \%$ \\
\hline & POSS-PRO & $5^{\circ} / 243$ & $20.58 \%$ & $84 / 230$ & $36.5^{2} \%$ & $5^{1 / 215}$ & $23.27 \%$ \\
\hline & POSS-REFL & $28 / 243$ & $11.5^{2} \%$ & $30 / 230$ & $13.04 \%$ & $29 / 215$ & $13.49 \%$ \\
\hline & POSS-GEN & $25 / 243$ & $10.29 \%$ & $28 / 230$ & $12.17 \%$ & $47 / 215$ & $21.86 \%$ \\
\hline \multirow[t]{7}{*}{ Swedish } & $\mathrm{BN}$ & $102 / 291$ & $35.05 \%$ & $20 / 208$ & $9.62 \%$ & $12 / 130$ & $9.23 \%$ \\
\hline & $-\mathrm{IN}$ & $26 / 291$ & $8.93 \%$ & $38 / 2 \circ 8$ & $18.27 \%$ & $14 / 130$ & $10.77 \%$ \\
\hline & DEN & $12 / 291$ & $4.12 \%$ & $9 / 208$ & $4.33 \%$ & $7 / 130$ & $5 \cdot 38 \%$ \\
\hline & DEM & $12 / 291$ & $4.12 \%$ & $12 / 208$ & $5 \cdot 77 \%$ & $9 / 130$ & $6.92 \%$ \\
\hline & POSS-PRO & $30 / 291$ & $10.31 \%$ & $47 / 208$ & $22.60 \%$ & $30 / 130$ & $23.08 \%$ \\
\hline & POSS-REFL & $13 / 291$ & $4.47 \%$ & $45 / 208$ & $21.63 \%$ & $21 / 130$ & $16.15 \%$ \\
\hline & POSS-GEN & $61 / 291$ & $20.96 \%$ & $21 / 208$ & $10.10 \%$ & $28 / 130$ & $21.54 \%$ \\
\hline \multirow[t]{7}{*}{ Icelandic } & $\mathrm{BN}$ & $25 / 166$ & $15.06 \%$ & 39 / 193 & $20.21 \%$ & $19 / 76$ & $25.00 \%$ \\
\hline & $-\mathrm{IN}$ & $30 / 166$ & $18.07 \%$ & $35 / 193$ & $18.13 \%$ & $11 / 76$ & $14.47 \%$ \\
\hline & DEN & $9 / 166$ & $5.42 \%$ & 8 / 193 & $4.15 \%$ & $6 / 76$ & $7.89 \%$ \\
\hline & DEM & $5 / 166$ & $3.01 \%$ & $8 / 193$ & $4.15 \%$ & $5 / 76$ & $6.58 \%$ \\
\hline & POSS-PRO & $32 / 166$ & $19.28 \%$ & $2 / 193$ & $1.04 \%$ & $14 / 76$ & $18.42 \%$ \\
\hline & POSS-REFL & $19 / 166$ & $11.45 \%$ & $33 / 193$ & $17.10 \%$ & $11 / 76$ & $14.47 \%$ \\
\hline & POSS-GEN & $18 / 166$ & $10.84 \%$ & $22 / 193$ & $11.40 \%$ & $6 / 76$ & $7.89 \%$ \\
\hline
\end{tabular}

In the case of indirect anaphora, as presented in Table 54, the picture becomes more complicated, as there is an abundance of forms with which the incipient definite article competes in this context. Apart from BNs and demonstratives, we also find possessives in the form of genitival NPs (tagged as POSSGEN) or pronouns, both regular (POSS-PRO) and reflexive (POSS-REFL). The results for -IN are inconclusive. While in Danish the proportion of -IN in indirect anaphors consistently grows over the periods, it fluctuates in Swedish and even declines in Icelandic. As expected, possessives are used very frequently in the context of indirect anaphora. In Swedish and Danish regular possessive pronouns are especially frequent: they constitute on average $27 \%$ of indirect anaphors in Danish and $19 \%$ in Swedish. In Icelandic possessive pronouns are not used quite as often in indirect anaphors, appearing in only ca. $13 \%$ of exam- 
TABLE 55 Expressions of larger situation use in the corpus

\begin{tabular}{|c|c|c|c|c|c|c|c|}
\hline \multirow{2}{*}{$\begin{array}{l}\begin{array}{l}\text { Unique } \\
\text { reference }\end{array} \\
\text { Danish }\end{array}$} & \multirow{2}{*}{$\begin{array}{l}\text { Forms } \\
\text { BN }\end{array}$} & \multicolumn{2}{|c|}{ Period I } & \multicolumn{2}{|c|}{ Period II } & \multicolumn{2}{|c|}{ Period III } \\
\hline & & $49 / 65$ & $75 \cdot 38 \%$ & $5^{6 / 115}$ & $48.70 \%$ & $70 / 112$ & $62.50 \%$ \\
\hline & $-I N$ & $4 / 65$ & $6.15 \%$ & $9 / 115$ & $7.83 \%$ & $20 / 112$ & $17.86 \%$ \\
\hline & DEN & $2 / 65$ & $3.08 \%$ & $13 / 115$ & $11.30 \%$ & $10 / 112$ & $8.93 \%$ \\
\hline & DEM & o/ 65 & $0.00 \%$ & $2 / 115$ & $1.74 \%$ & $2 / 112$ & $1.79 \%$ \\
\hline \multirow[t]{4}{*}{ Swedish } & $\mathrm{BN}$ & $85 / 109$ & $77.98 \%$ & $63 / 107$ & $58.88 \%$ & $16 / 26$ & $61.54 \%$ \\
\hline & $-I N$ & $5 / 109$ & $4.59 \%$ & $14 / 107$ & $13.08 \%$ & $6 / 26$ & $23.08 \%$ \\
\hline & DEN & o / 109 & $0.00 \%$ & $3 / 107$ & $2.80 \%$ & $1 / 26$ & $3.85 \%$ \\
\hline & DEM & o / 109 & 0.00\% & $0 / 107$ & $0.00 \%$ & $\mathrm{o} / 26$ & $0.00 \%$ \\
\hline \multirow[t]{4}{*}{ Icelandic } & $\mathrm{BN}$ & $17 / 28$ & $60.71 \%$ & $8 / 19$ & $42.11 \%$ & $2 / 4$ & $50.00 \%$ \\
\hline & $-I N$ & $\mathrm{o} / 28$ & $0.00 \%$ & $4 / 19$ & $21.05 \%$ & $2 / 4$ & $50.00 \%$ \\
\hline & DEN & $\mathrm{o} / 28$ & 0.00\% & $1 / 19$ & $5.26 \%$ & $0 / 4$ & $0.00 \%$ \\
\hline & DEM & $1 / 28$ & $3.57 \%$ & $0 / 19$ & $0.00 \%$ & $0 / 4$ & $0.00 \%$ \\
\hline
\end{tabular}

ples. Reflexive possessive pronouns are at least equally frequent as -IN in this context in all languages. The genitive is quite frequently used in Swedish $(17.5 \%$ of all indirect anaphors on average), and almost as frequently in Danish $(14.8 \%$ on average). Icelandic does not make such a frequent use of the genitive as the other languages (it accounts for only $10 \%$ of examples). Overall, possessives are used much more frequently indirect anaphors in Swedish and Danish than in Icelandic.

In the case of larger situation use, as presented in Table 55, there is a persistent high frequency of BNs for all languages and all periods. The proportion of -IN in unique reference, even though not very high, exhibits steady growth over the three periods. Here it is important to note that the results for Icelandic are of lower statistical significance, as there are fewer examples of unique reference than in the other two languages. In the Icelandic corpus unique referents occur only in $1.6 \%$ of all NPs ( 51 examples), compared with $8.3 \%$ (242 examples) and $10.1 \%$ (292 examples) for the Swedish and Danish corpora respectively. This disparity is due to the presence of religious texts in the Swedish and Danish corpora, but not in the Icelandic corpus. 


\subsection{All Factors-A Refined Analysis}

In this chapter we have examined the interdependencies between definiteness (and indefiniteness) and a number of factors, such as case, number, gender and animacy. Each of these factors was discussed individually. We noted that some values favoured the definite article early on, e.g., nominative case, subject function, masculine gender and animacy, while others disfavoured the definite article, e.g., neuter gender and inanimacy. Even from these individual analyses we obtain a picture of an NP that is most likely to be definite in Period I in all languages in the sample, as well as a picture of an NP that is least likely to be marked with -IN in that period. We can also discern how the factors change over time.

In this section we will study the data more globally. In particular, we present statistics revealing the influence of particular values on the choice of NP form between defNP, indefNP and BN. This influence is presented as a weight: factors favouring selection of a particular NP form have positive values, while those disfavouring selection of the form have negative values. In the case of positive values, the higher the values for a given factor, the stronger is its explanatory power. Apart from the weight, we also present the relative score, that is, we order the values from the most favourable to a given form to the least favourable. A relative score of +100 means that if the factor (e.g., nominative case) is present, the form will always be chosen, while a relative score of -100 means that the presence of the factor excludes the possibility of using the form; for example, number_plural excludes indefNP.

The calculated weights come from applying a regression algorithm on all gathered data. The aim of the algorithm is to produce a mathematical function that will take all properties of a word (case, singularity, anaphora ...) as input and return the definiteness of this word. Theoretically, this function could be applied to any word with known properties and the definiteness of the word would be automatically calculated. This function, however, would not always return correct values due the fact that not all linguistic phenomena can be modelled accurately and globally for all words. Therefore, the construction and evaluation of such a function was not the primary goal of the research. The function was, indeed, constructed, but for the purpose of retrieving the weight values it applies to different linguistic properties of words. These weights reflect the impact of each individual property on the definiteness of the word. The relative score of a feature is calculated as the percentage of the weight of this feature compared to the weight of the feature which has the strongest impact on the definiteness (i.e., has the highest weight). 
Further research plans include examining the impact of pairs or sets of features (like masculine + direct anaphora) on the definiteness of the word. Such calculations require modifications of the regression algorithm.

\subsubsection{The Definite Article}

Factors favouring the use of -IN in Danish in Period I are genitive case, masculine gender, and the function of direct anaphora. -IN is disfavoured by both subjects and objects, but less so by subjects; the relative score for objects is almost twice as high as for subjects. Animacy and feminine and neuter gender have similar relative scores. Factors clearly disfavouring the use of -IN are abstractness of the noun and the oblique or no-ending form of the noun.

In Swedish the factors most favourable to the selection of -IN in Period I are the function of direct anaphora, masculine gender and singular number. Animate nouns are more favoured than inanimate, while nominative case is the least favourable of the four basic cases. Plural number and abstractness of the noun strongly disfavour the use of -IN. Only one factor favours the selection of -IN in Icelandic in Period I, namely the function of direct anaphora. Of those that disfavour it the least, the most notable are subject function and nominative case; masculine gender appears surprisingly low on this scale. The use of -IN is, surprisingly, more favoured with inanimate referents than with animate ones.

We may conclude that direct anaphora is a common factor favouring the selection of -IN in Period I in all three languages. Danish and Swedish produce similar results with respect to subject function and masculine gender, but differ in how they treat animate and inanimate nouns.

In Period II in Danish, accusative case and direct anaphora are the strongest variables favouring the incipient definite article (-IN). Dative case and neuter gender also favour -IN, while, surprisingly, the masculine gender is resistant to the occurrence of -IN in all three languages in this period. Factors that strongly disfavour -IN are again the abstractness of the NP, as well as mass nouns and plural number.

In Swedish direct anaphora remains the strongest predictor for-IN, followed by the function of subject and genitive case. Plural and abstract nouns remain strong 'repellents' of -IN, together with the oblique case and no-ending forms of the noun. Animacy is not a strong predictor for either Swedish or Danish, but in both languages animate nouns have a higher relative score than inanimate ones. In Icelandic, similarly to Danish, direct anaphora and accusative case are the strongest variables favouring -IN. Among the factors that strongly disfavour -IN are oblique case, mass and abstract nouns, and plural number. Again, inanimate nouns are higher on the scale than animate nouns, in contrast to the other two languages. 


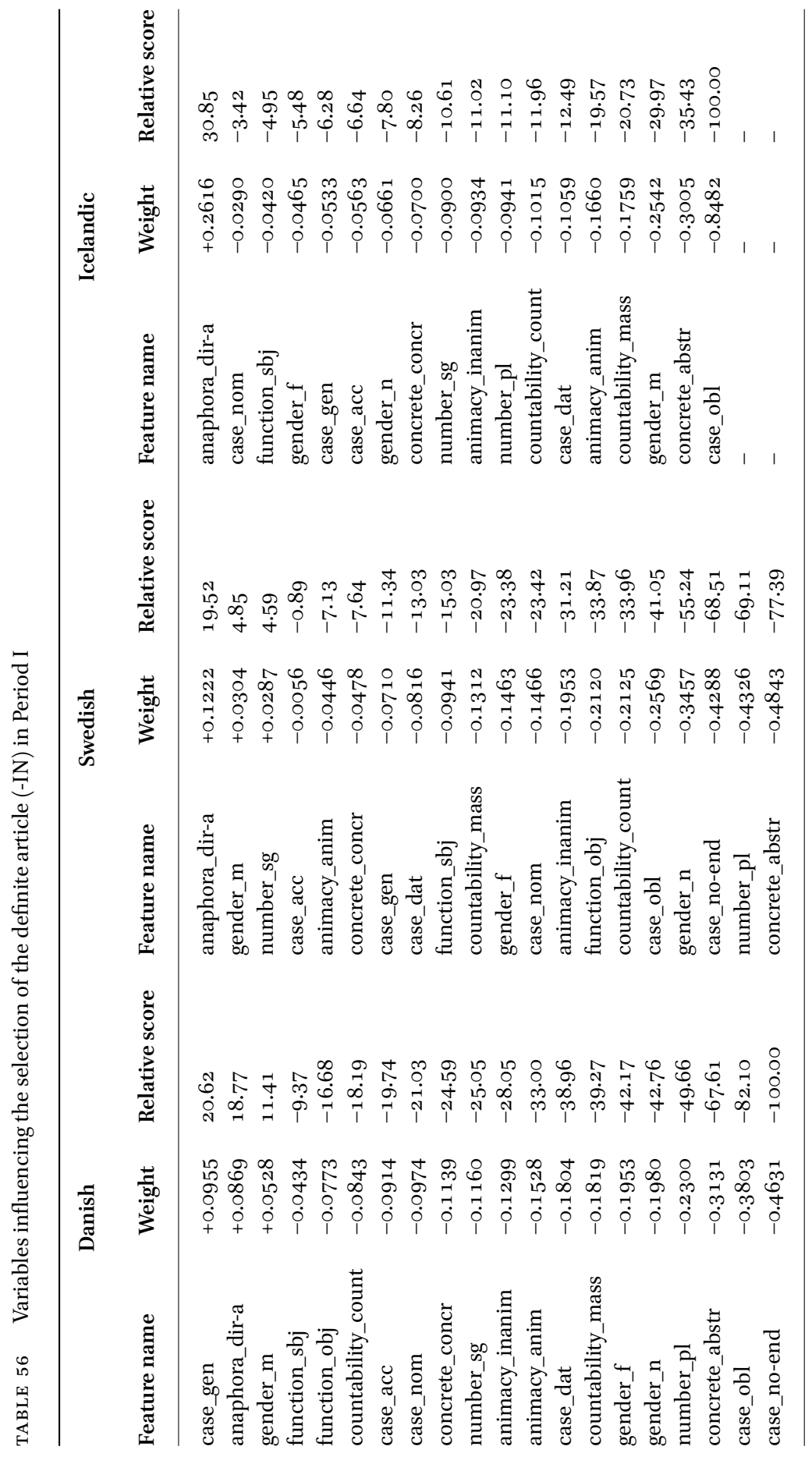




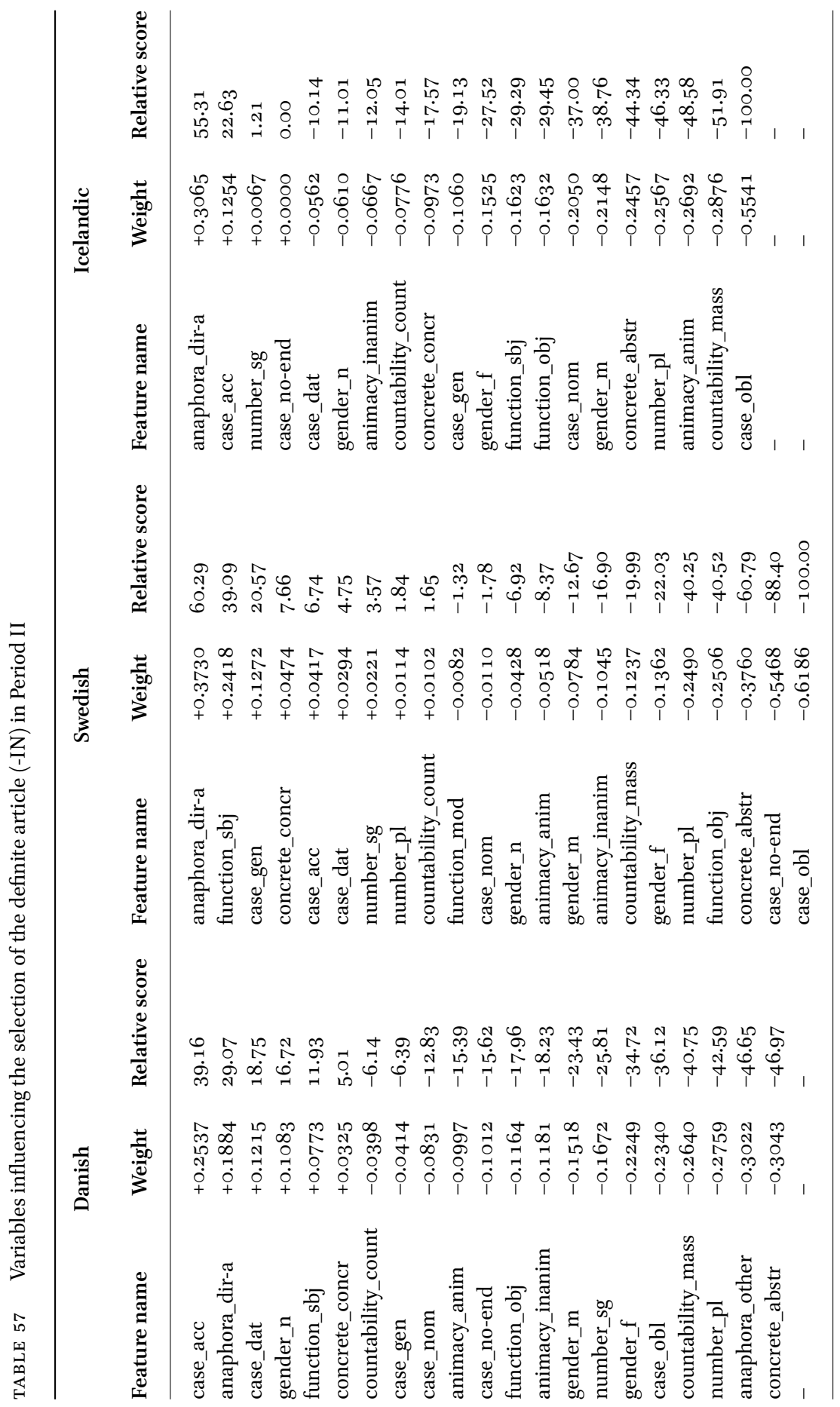




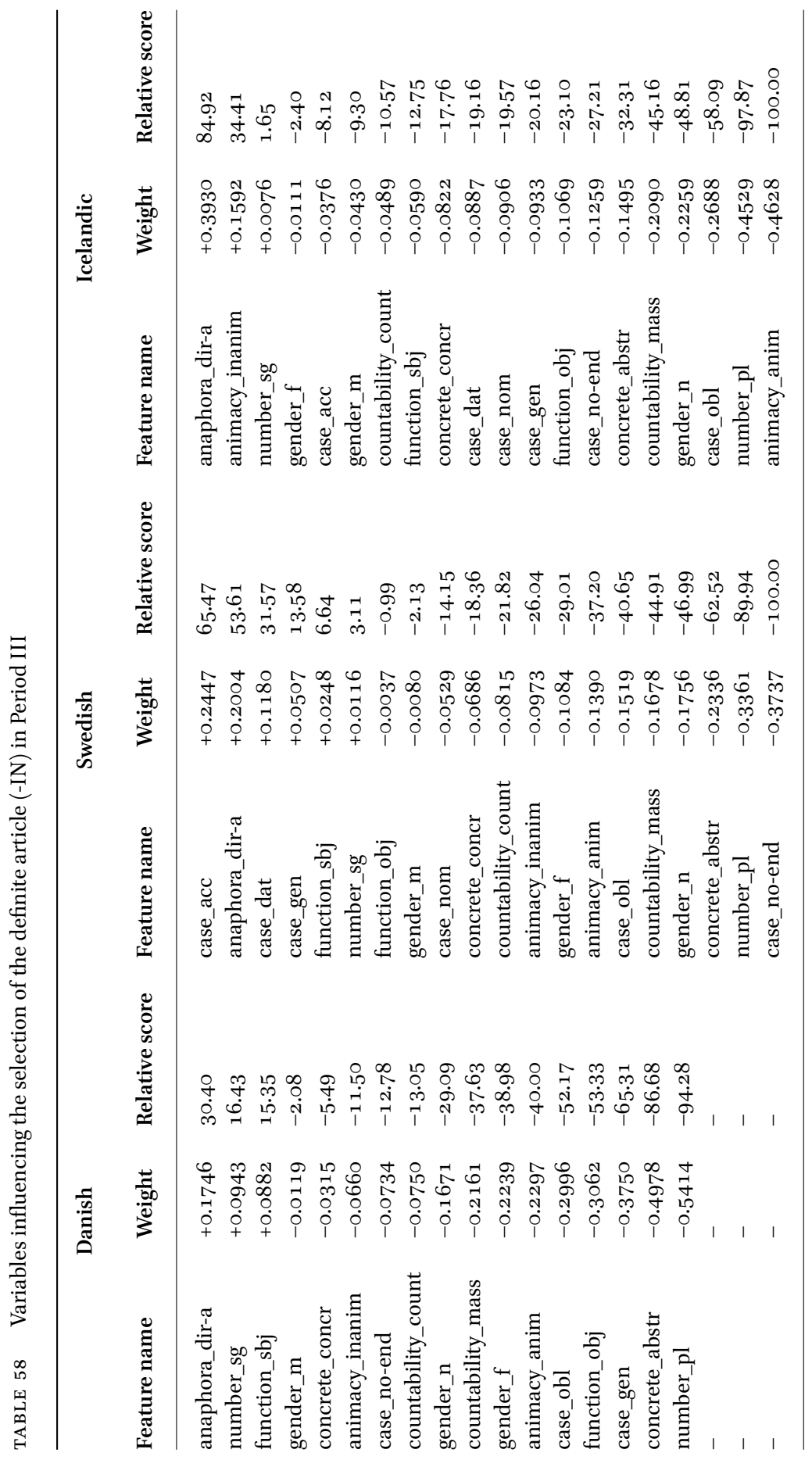


Direct anaphora, singular number and subject function remain the strongest predictors of definiteness in Period III. Inanimacy is no longer a strong repellent for -IN, and inanimates 'climb up' the scale. The decline of the case system in Swedish is visible in the results, even though the oblique cases rank highly with respect to how strongly they favour the appearance of -IN, the nominative is classed very low. In Danish the cases have disappeared as an explanatory factor, apart from genitive and oblique forms or no ending forms. Interestingly, in the Icelandic texts in the corpus the definite article has a strong preference for inanimate nouns, while animate nouns are strongly disfavoured.

\subsubsection{The Indefinite Article}

Only in Icelandic do we find factors favouring the selection of EN in Period I, all related to case. The disfavouring factors include plural (as we would expect) and mass values, as well as abstract nouns. Surprisingly, the genitive case in Danish and the object function in Icelandic also strongly disfavour the occurrence of the indefinite article in Period I.

In the second period, only in Danish are there more factors favouring the indefinite article. It is the nominative case and countable nouns that are preferred by EN. In Swedish the function of subject has the highest relative score; this is most likely due to the frequency of the presentative construction. The factors that are the strongest repellents of EN include the plural, as well as direct anaphora and mass and abstract nouns. The results for all languages are quite uniform in Period II.

In the third period, in Danish EN is preferred in the function of adverbial and in singular NPs. In Swedish it is preferred in the function of predicative, albeit the relative score is not very high. As in the previous periods EN is strongly disfavoured with plural and mass NPs, as well as with direct anaphora.

\subsubsection{The Definite Article vs. Bare Nouns-Classification Tree Analysis}

Lastly, to ascertain which independent variables have the greatest influence on the presence of the definite article in our dataset on a larger scale, we perform a classification tree analysis. Since we have already presented detailed results for each language and period in sections 4.9.1 and 4.9.2, here we aim to present more global results, treating all three languages together. Further, the classification trees for different languages did not vary to a significant degree, thus we deem that displaying one figure per period is a good enough generalization. The classification tree analysis tests each independent variable separately and chooses the variable that has the greatest association with the response. The algorithm then splits the data into subsets or classes, which can be visu- 


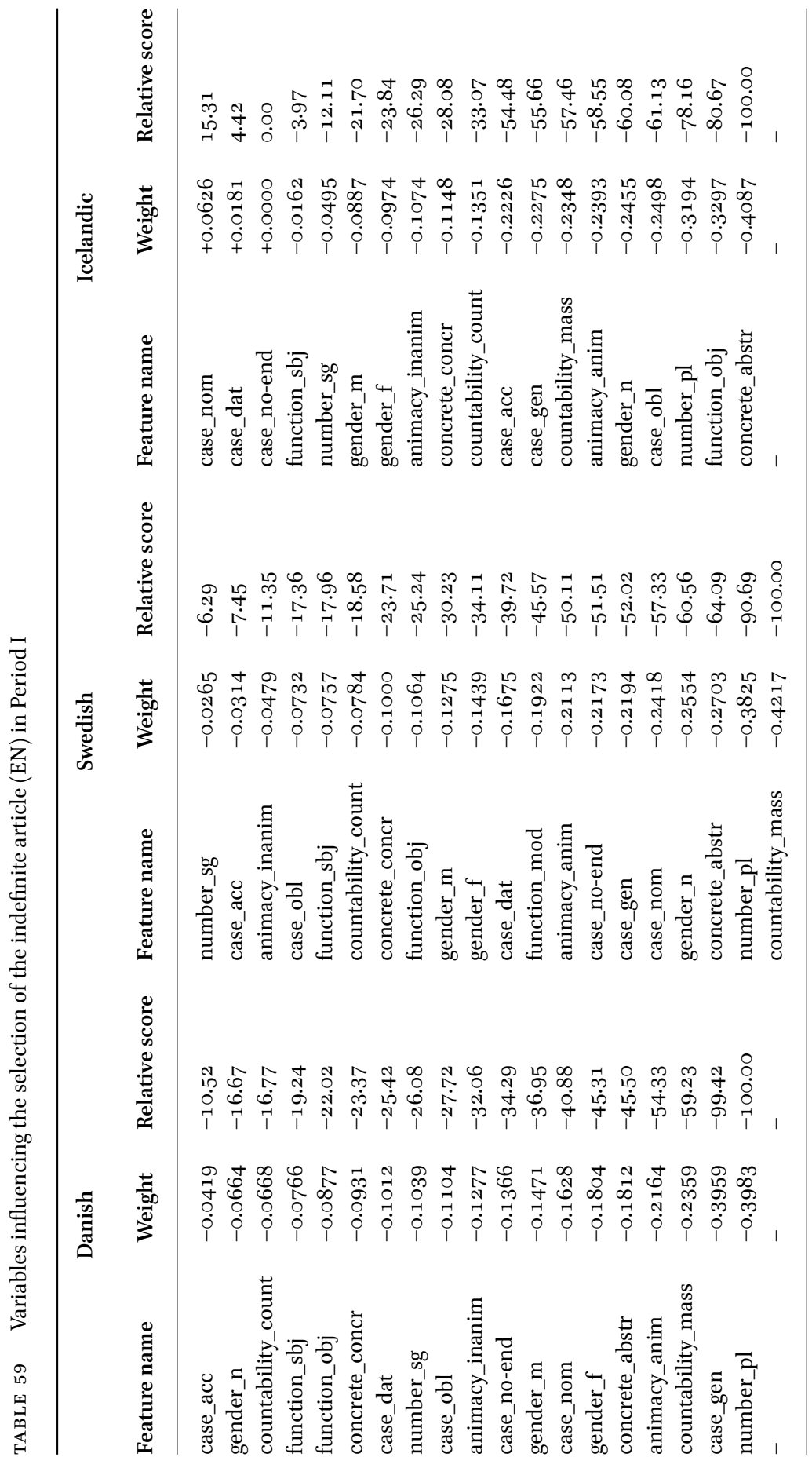




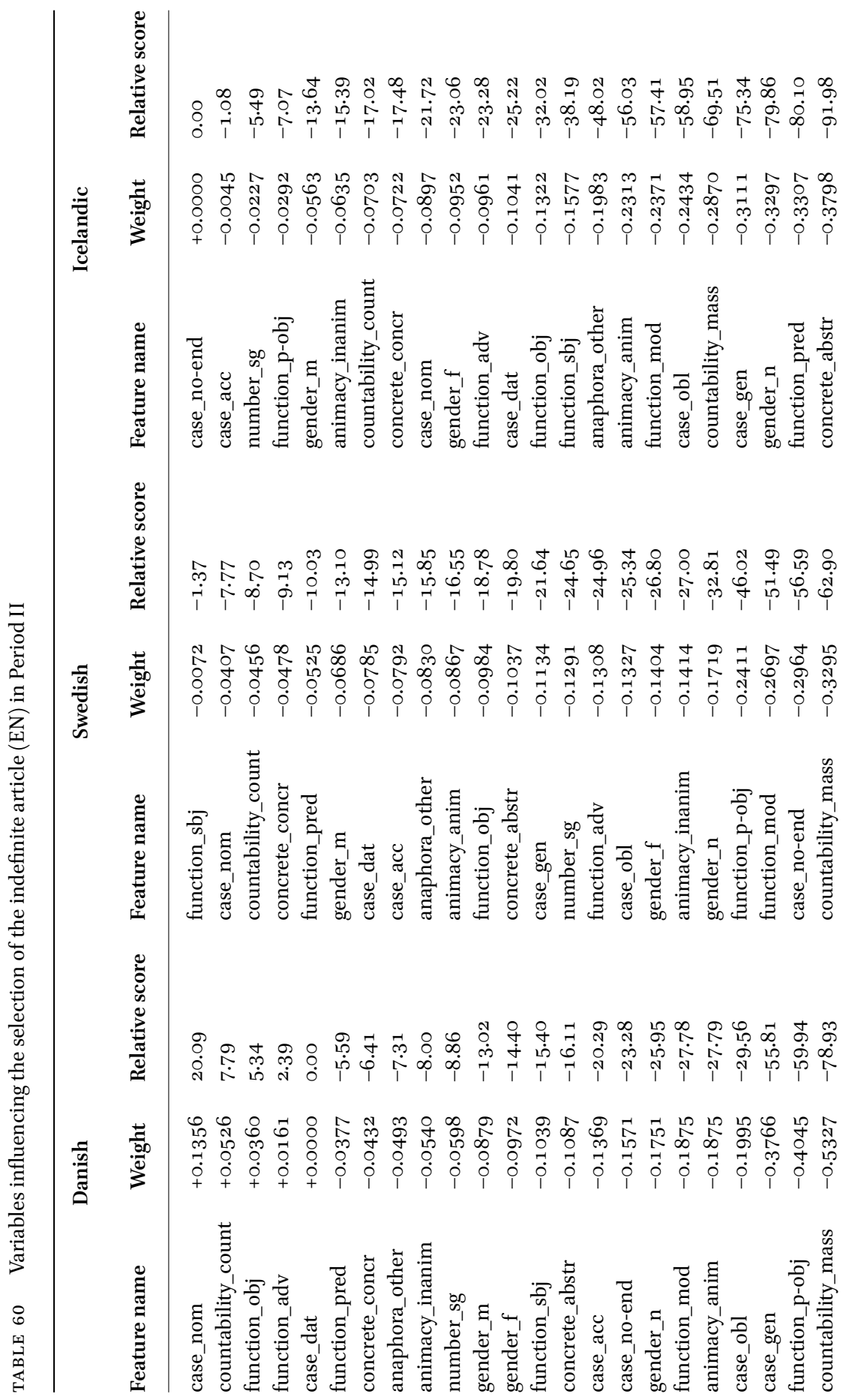




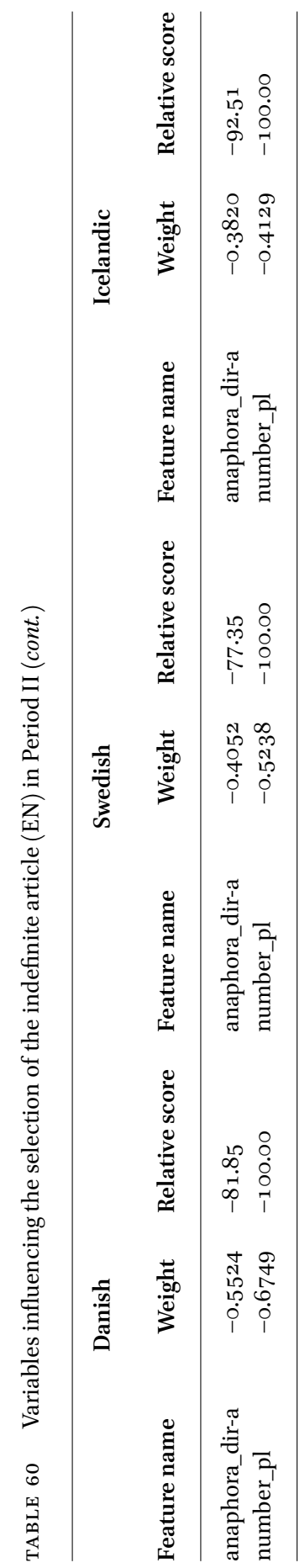




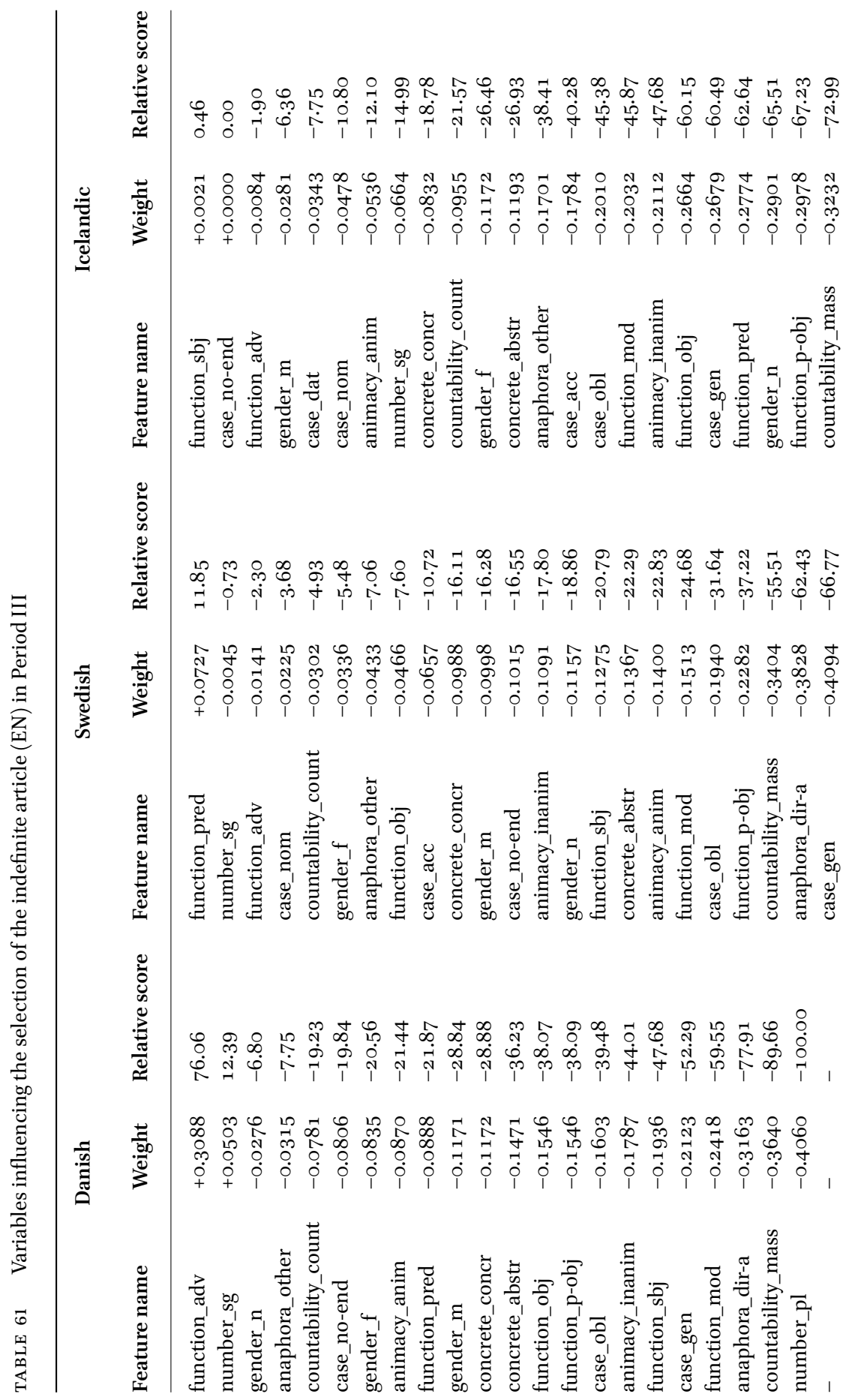




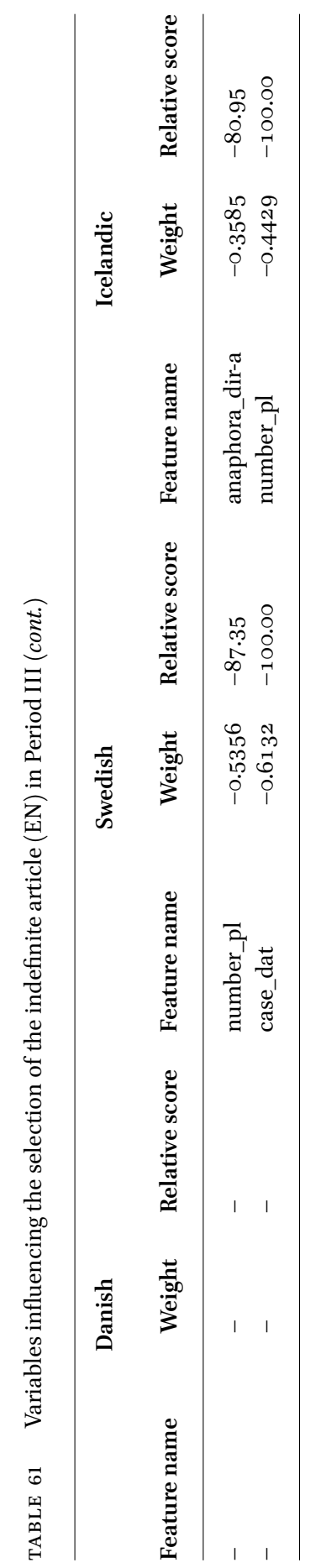




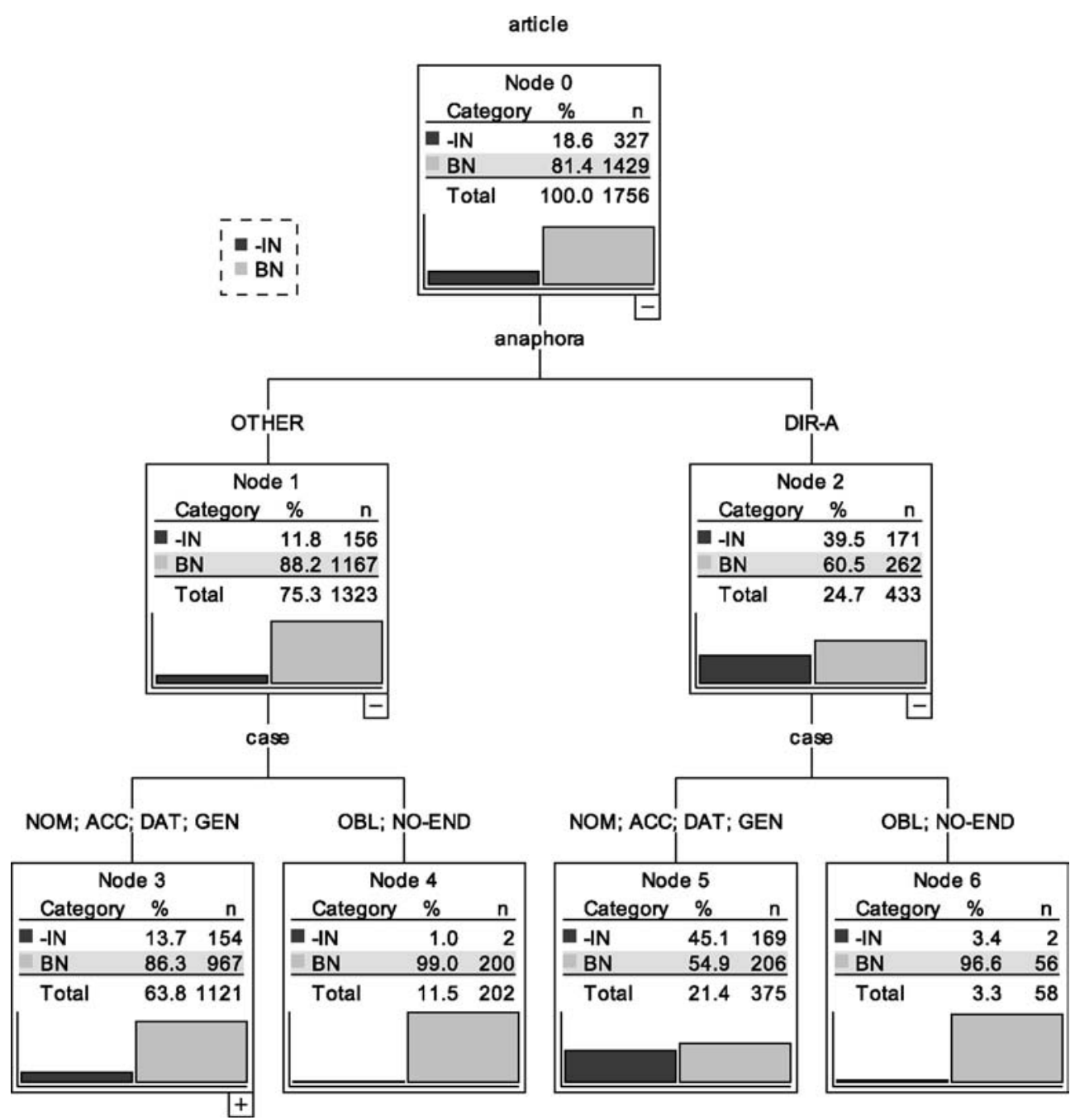

FIGURE 11 Classification tree for Period I (1200-1350)

alised in the form of 'trees' with several 'branches' and 'leaves' (i.e., nodes). For each period, the trees presented below compare instances of the definite article $(-\mathrm{IN})$ and bare nouns $(\mathrm{BN})$.

In Period I there are overwhelmingly more bare nouns than definite NPs (see Fig. 9). Thus, even though the analysis finds statistically significant splits, bare nouns dominate at every node. In the first split, we observe that direct anaphora is associated with a higher proportion of definite NPs (Node 2). Out of all direct anaphors, NPs in the nominative, accusative, dative and genitive are much more likely to be definite (Node 5 ) than NPs in the oblique case or 


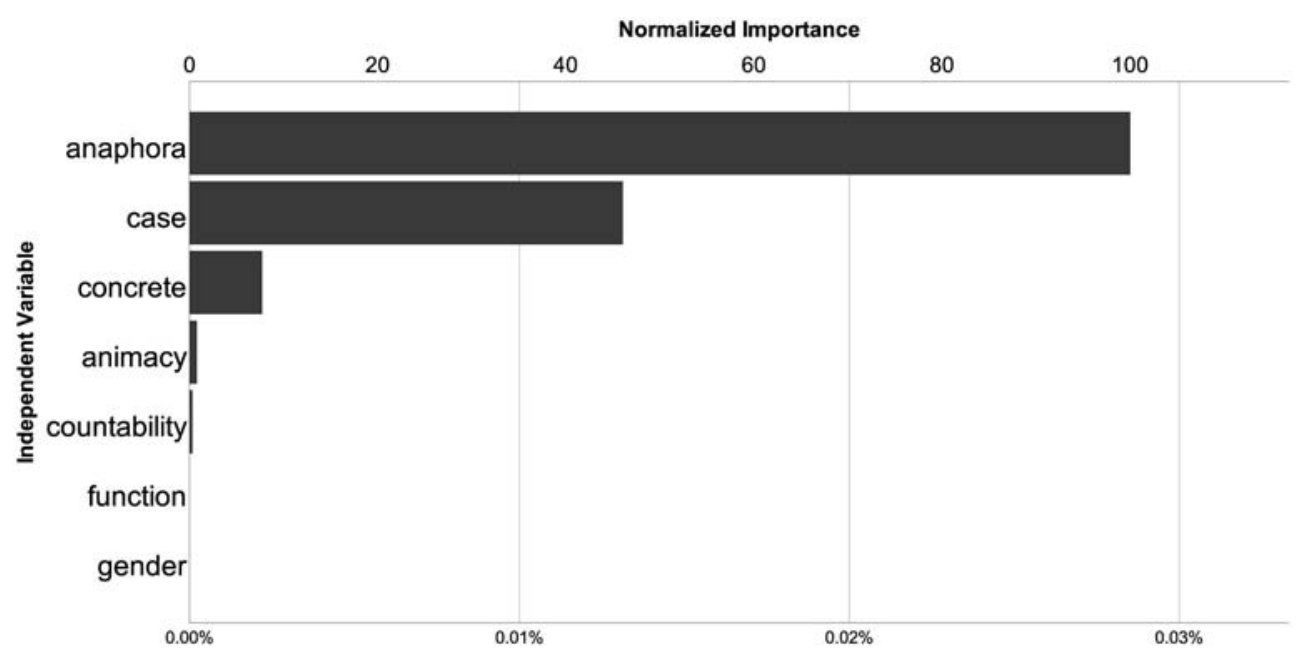

FIGURE 12 The importance of each independent variable in Period I

those with no ending (Node 6)..$^{5}$ On the left side of the graph, we observe a similar tendency; namely that, if -IN is used in other types of reference than direct anaphora, it appears almost exclusively in the nominative, accusative, dative and genitive.

The tree analysis also provides us with an assessment of the impact of individual predictors on the model. In Figure 10, the importance of the predictors in Period I is presented. The most important predictor, anaphora, has the highest relative value of importance (100\%), and the others are displayed as percentages of that value. The second most influential predictor of the definite article in Period I is case, while the remaining variables are virtually irrelevant.

Unfortunately, due to the large imbalance in the numbers of definite NPs and bare nouns, the model presented in Figure 9 does not offer an improvement in accuracy. Whether or not the independent variables are included, the model predicts $81.4 \%$ of cases correctly, which is the exact number of BNs in the model. Thus, a model predicting that all cases will be BNs would also be correct in $81.4 \%$ of cases.

In the second period, definite NPs are more frequent in the material, resulting in a more balanced classification (see Fig. 11). The first split is yet again deter-

5 The four examples with -IN and OBL/NO-END listed in Nodes 4 and 6 are instances of weak nouns in which the ending is not a proper case ending even with a definite article, but rather a non-nominative case ending, as in pripiung af bono 'a third of the property' (SV_AVL, Period I). 


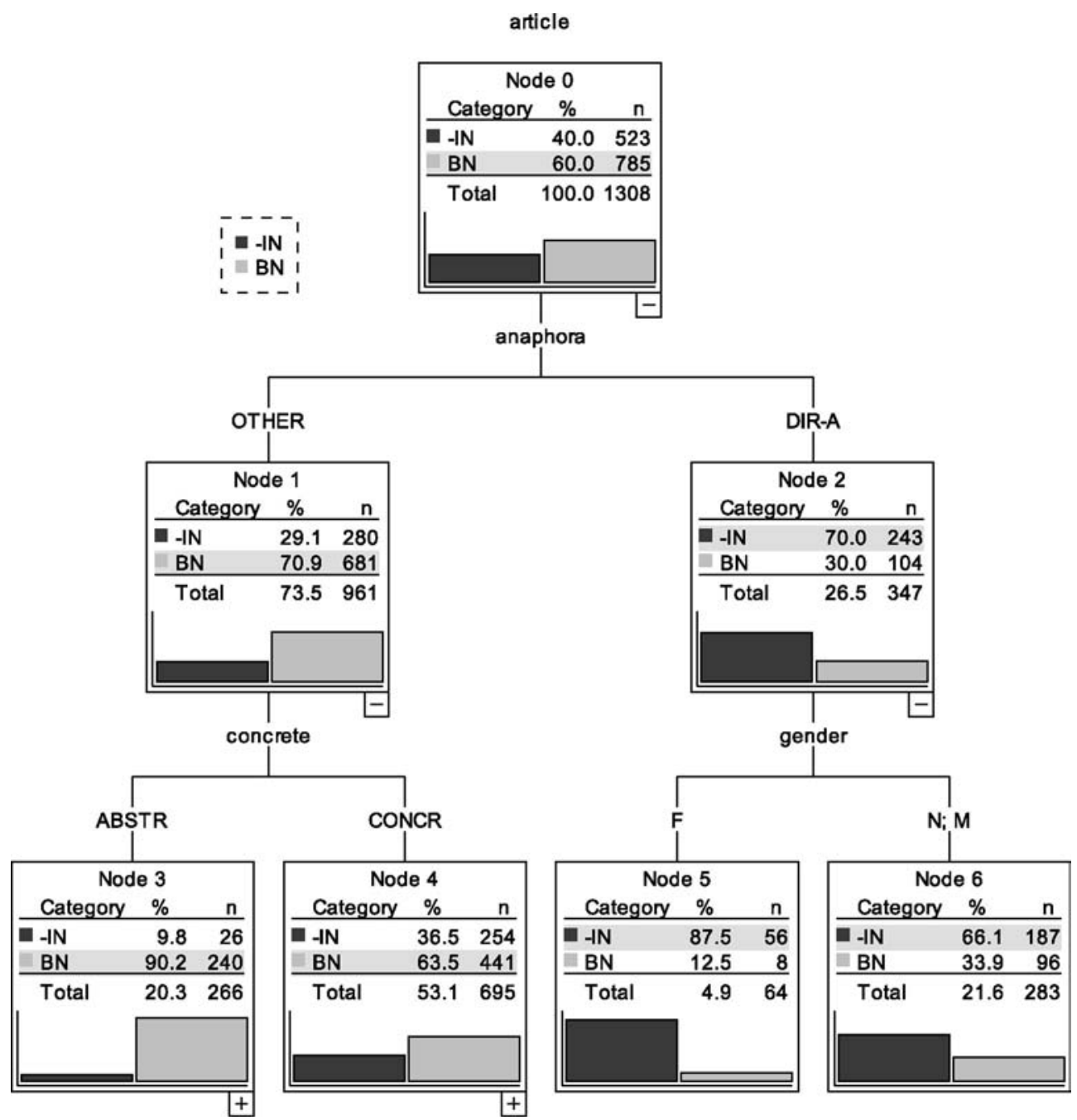

FIgURE 13 Classification tree for Period II (1350-1450)

mined by the presence of direct anaphoric reference. Definite NPs are much more frequent in direct anaphora than bare nouns (Node 2). Within direct anaphora, the second split in our tree is determined, quite surprisingly, by gender. Thus, the definite article is most likely to occur in Period II in feminine NPs that are used anaphorically (Node 5). An explanation of this unfortunately cannot be found in correlation with case, as one reviewer suggests, since feminine accusatives or datives are in no way more frequently marked with -IN in this period than masculine or neuter nouns. The selection of feminine gender as significant in Node 5 is of little importance for overall results (compare 


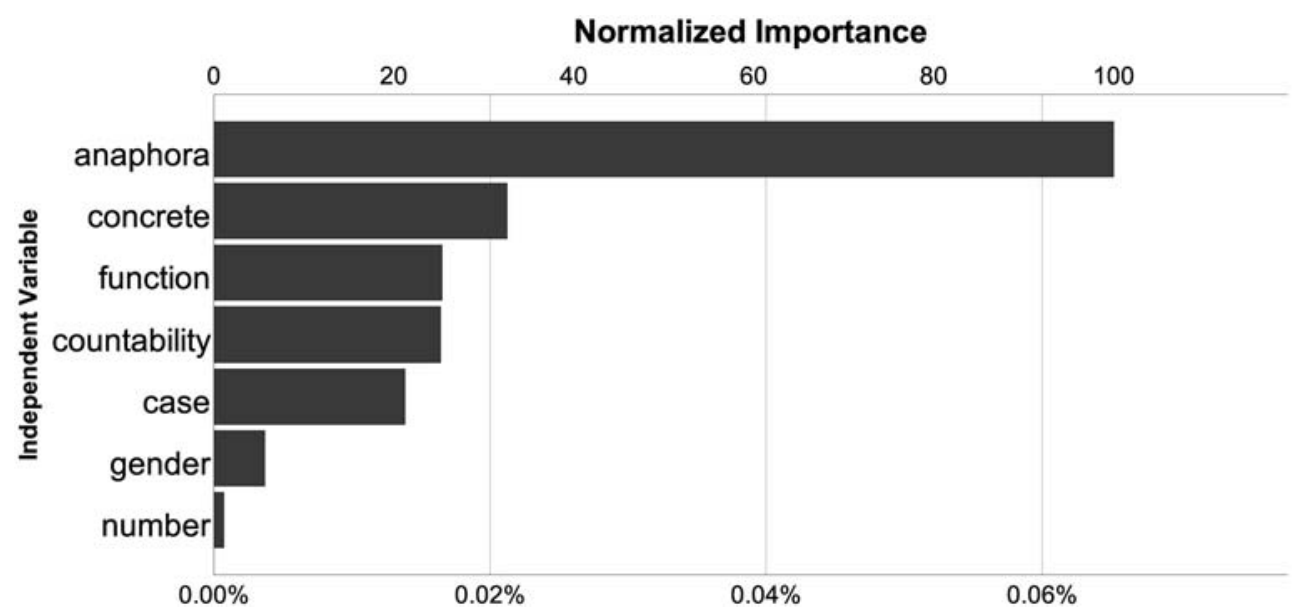

FIGURE 14 The importance of each independent variable in Period II

with Table 57 which illustrates that feminine gender is not higher in its relative score than other genders for either of the languages, and with Figure 12 below which will reveal that the weight of the factor of gender is not particularly large). In this case, the classification tree seems to be overfitting the data, namely feminine nouns are not particularly frequent in the corpus, but it so happens that they are unusually frequent in Swedish texts from Period II (relative to other languages and periods). Thus, even though feminine gender is overall not a strong factor in predicting whether the definite article will be used, it is selected as significant in Figure 11 due to an unusual high frequency of feminine nouns in Swedish texts from this period. Further, within reference other than direct anaphora (Node 1) the incipient definite article occurs more frequently with concrete rather than abstract nouns (Nodes 3 and 4), although bare nouns dominate here in both categories.

Figure 12 reveals that anaphora is again the most important predictor of -IN. Such variables as concreteness of the NP, syntactic function, countability and case are also relevant for the model, as is gender, albeit to a smaller degree.

As regards the goodness-of-fit of the model, if the algorithm assigned the type of the NP trivially, guessing that all cases are BNs, it would be correct in $60 \%$ of cases. That is our baseline model. The tree classification for Period II offers some improvement over the baseline model, as its accuracy is measured at $71.6 \%$. This means that the inclusion of the independent variables has a positive impact on the model.

In Period III (see Fig. 13), anaphoric reference determines the first split, which results in almost identical subsets to those determined for Period II. Within direct anaphora, case is the predictor that resolves the second split. 


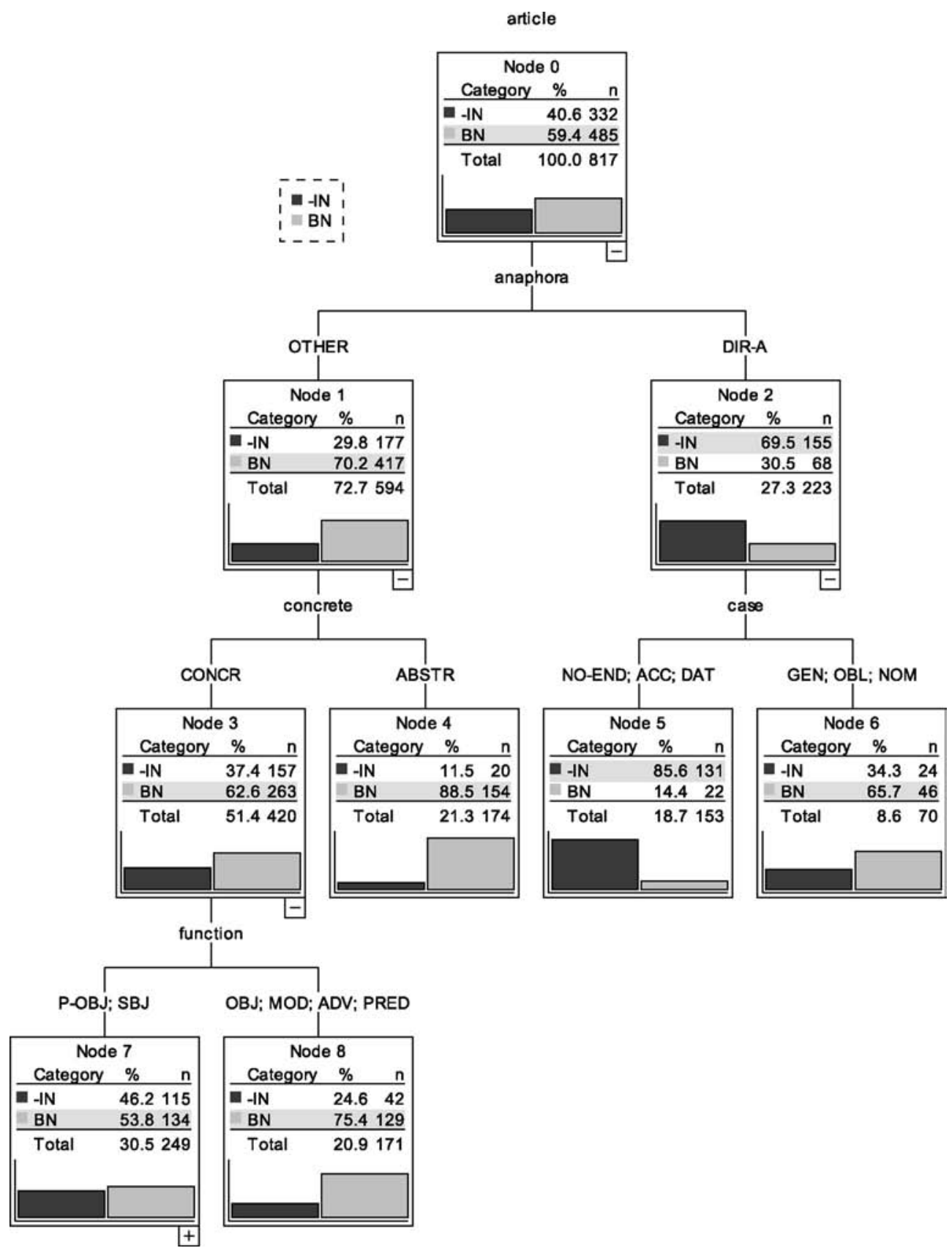

FIGURE 15 Classification tree for Period III (1450-1550) 


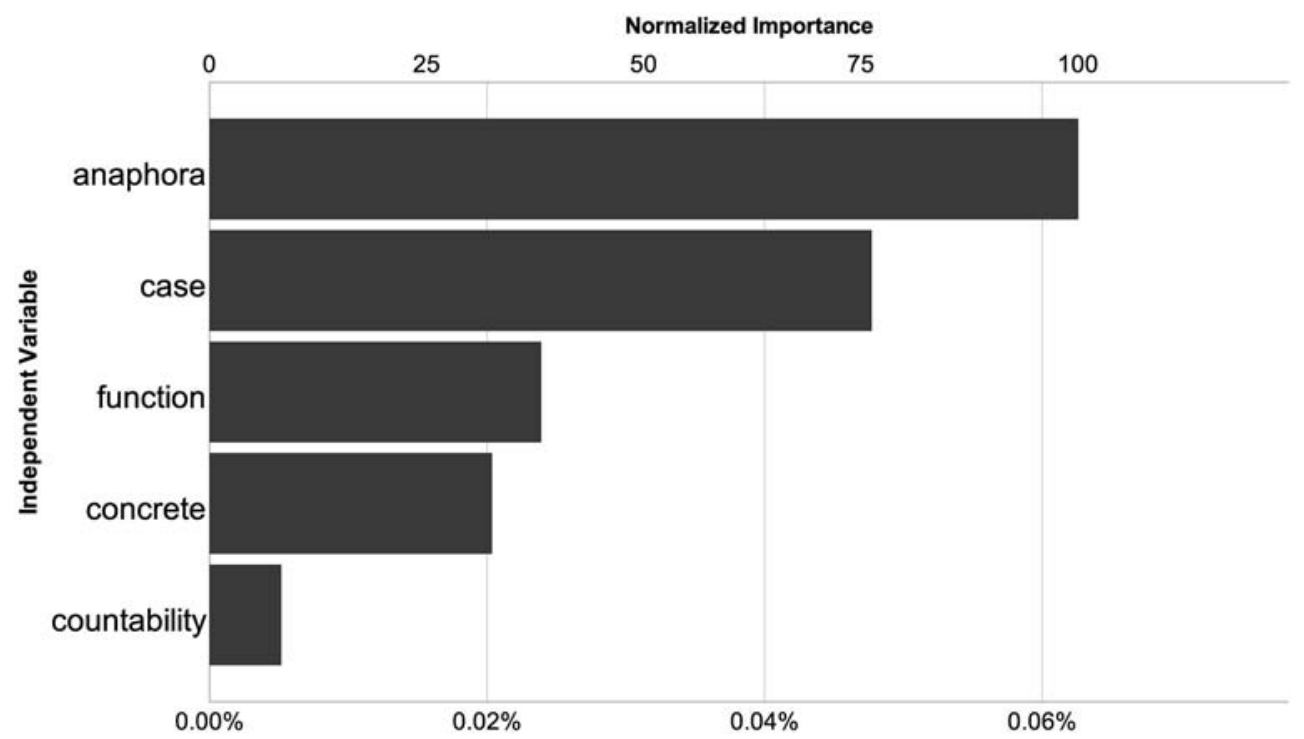

FIGURE 16 The importance of each independent variable in Period III

Here, definite NPs are used more frequently with nouns in the accusative or dative or nouns with no ending (Node 5), while bare nouns are used more often with nouns in the genitive, oblique or nominative case (Node 6). On the left side of the tree, if there is no direct anaphoric reference, definite NPs are more likely to occur with concrete than abstract nouns (Nodes 3 and 4). Among non-anaphoric, concrete NPs, the definite article occurs more frequently in the subject or prepositional object position (Node 7) than it does with other syntactic roles.

Anaphoric reference remains the most important predictor, closely followed by case (see Fig. 14). The syntactic function and concreteness of the NP are also relevant variables. The accuracy of the baseline model is $59.4 \%$ (i.e., the number of BNs in this period). The classification tree offers a significant improvement over the baseline, as it predicts $74.4 \%$ of the cases correctly. Of the three models presented in this section, the model for Period III is the most accurate.

Overall, the results of the classification tree analysis confirm our previous findings, presented in section 4.9.1, that direct anaphora is the strongest predictor for definite NPs throughout all of the studied periods. The other predictors that were selected as significant, such as case, function and concreteness, were also ranked relatively high for each language, as we indicated in section 4.9.1. It is, however, important to bear in mind that the classification tree analysis presented here compares definite NPs with bare nouns only. Thus, animacy, for 
instance, may not be a highly ranked predictor when -IN is compared with BNs. However, this does not mean that animacy has no influence on the presence of -IN.

\subsection{Summary}

The qualitative analysis has revealed a number of facts about the incipient articles in Danish, Swedish and Icelandic, revealing different patterns in each language. As early as 1200 there is a palpable difference between the Continental and the Insular languages, despite many superficial similarities. On the whole, Icelandic is considered to be the language in which grammaticalization has proceeded furthest in Period I, judging by the stability and similarity of the results in the successive periods. Danish and Swedish, on the other hand, exhibit varied patterns, with many changes taking place from Period I to II and from Period II to III. In particular, a number of other changes taking place in Old Danish and Old Swedish at that time are reflected in the results, such as the decline of the case system, which took place in Danish a little earlier than in Swedish, but which is complete in both languages by the end of the studied period.

The data suggest that these developments were influenced by both semantic and syntactic properties of nouns, in particular animacy and subjecthood. Comparing the proportions of singular, animate subjects in all NPs and in defNPs we conclude that at the early stages of grammaticalization the definite form favours such referents over inanimate, mass or plural NPs in functions other than the subject. Also, the indefinite article, at its earliest stages of development, is associated with animate subjects, but it is less sensitive to animacy and case than the definite article. In fact, it seems that at the onset of indefinite article grammaticalization the development of the definite article is mirrored in the development of the indefinite, so that salient discourse referents are the first to receive regular article marking, but the factors which remain important for successive stages of definite article grammaticalization are not as significant with indefinite article grammaticalization.

The quantitative results confirm hypotheses advanced by, among others, De Mulder and Carlier (2011), that at the beginning of definite article grammaticalization pragmatic factors, in particular the salience of the discourse referent, play a significant role. The results also lend strength to the proposed model of grammaticalization of the indefinite article, revealing a surprising affinity of the incipient indefinite article with the subject function (in Danish and Swedish, Icelandic not having developed the indefinite article at all). 
Despite their mutual differences, one variable has been demonstrated to greatly favour the definite article in all of the languages studied, namely direct anaphora. Annotating the texts for the types of use of articles was a formidable task, and one that we believe can be done more justice in a qualitative study of these contexts. This is the subject of Chapter 5 . 